\title{
La ética del desarrollo humano y las Frontiers of Justice de Martha Nussbaum
}

\author{
Des Gasper
}

MARTHA NUSSBAUM, 2006

Frontiers of Justice.

Disability, Nationality, Species

Membership

Harvard University Press, Cambridge,

Massachusetts, 487 pp.

\section{INTRODUCCIÓN}

Martha Nussbaum ha elaborado un planteamiento

para el desarrollo humano que no solamente apunta a la evaluación de situaciones y acciones, sino que contribuye también a la descripción, el entendimiento y la inspiración. En este ensayo intento, primero, poner en claro esa variedad de propósitos y la correspondiente gama de métodos. Podemos, así, ver el enfoque de capabilities

DES GASPER: Instituto de Estudios Sociales de La Haya, Países Bajos. gasper@iss.nl

Traducción del inglés: Ángel Javier Dorantes y Sotomayor. Revisión: Juio Boltvinik.

Desacatos, núm. 23, enero-abril 2007, pp. 291-318.

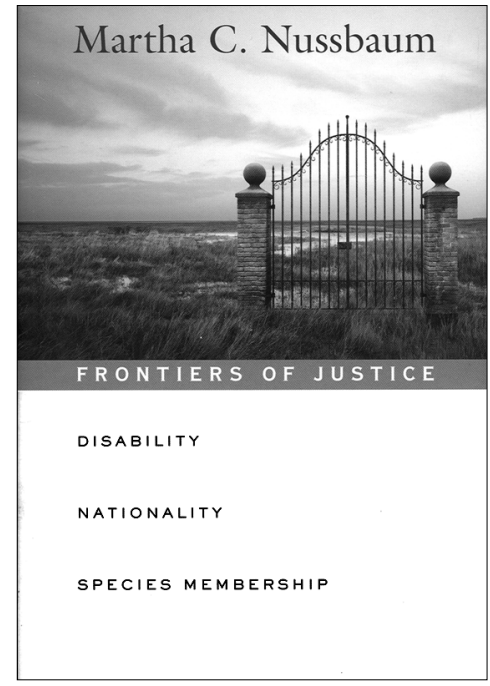

291 de Nussbaum —incluyendo su lista de capabilities ${ }^{1}$ prioritarias—, como parte de una concepción integral de la ética, incluyendo observación y práctica relacionadas con ella. En este contexto, la segunda parte del ensayo hace un repaso de los principales debates en torno al enfoque de capabilities de Nussbaum, considera cómo la versión que ella ha publicado desde 1998, revisada y profundizada, responde a comentarios anteriores, y ve cómo su nuevo libro Frontiers of Justice ${ }^{2}$ (Fronteras de la justicia) se

\footnotetext{
${ }^{1}$ Cualquier traducción de 'capability', tal como la usa Amartya Sen, tiende a darle una precisión que no tiene en su obra y que, por tanto, resultaría falsa. La opción menos mala, entonces, es la de dejarla en inglés. [Nota del coordinador del número, Julio Boltvinik.] ${ }^{2}$ No hay traducción al español. [Nota del coordinador del número, Julio Boltvinik.]
} 


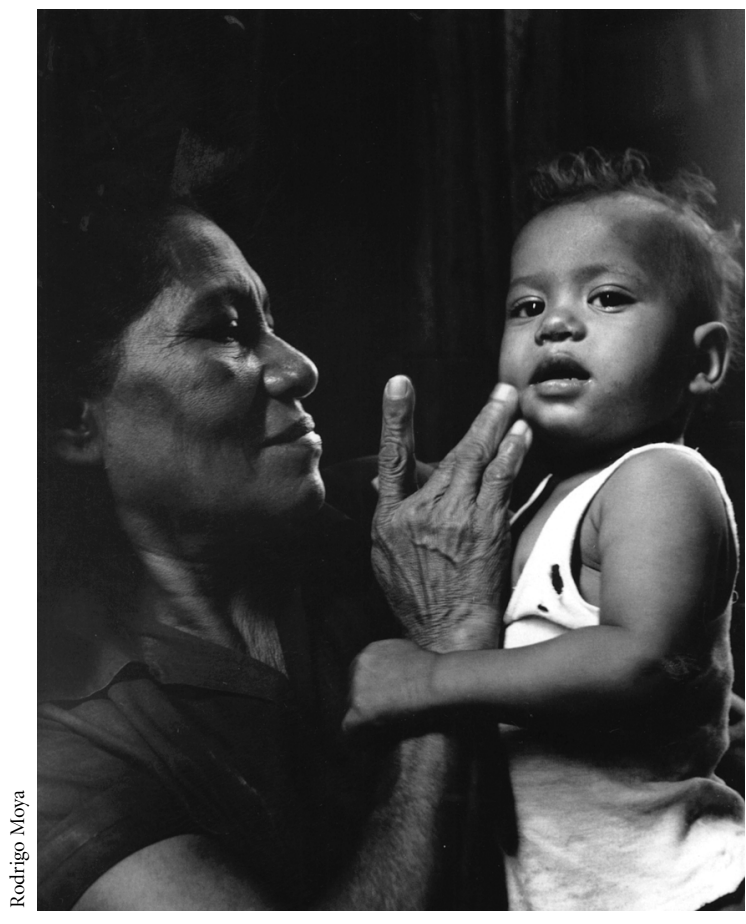

Barrio El Chorrillo, Panamá, Panamá, 1965.

extiende a temas que van más allá del alcance de casi todas las teorías de la justicia. La tercera parte revisa directamente los métodos recomendados por Nussbaum: comprometerse con un amplio espectro de elementos de evidencia, incluyendo relatos personalizados; el uso especial de literatura narrativa y otros tipos de literatura ideográfica para crear interés y simpatía; el análisis y uso de la emoción, con especial énfasis en la compasión; y una prioridad concedida a la "crítica interna", esto es, al diálogo con una tradición cultural movilizando sus propios recursos internos. Consideraremos la razón de ser de estos métodos, hasta qué punto Nussbaum ha respetado sus principios y qué tanto podría abrirse a otros tipos de evidencia, colaboración e interacción. Veremos tanto las fortalezas como las debilidades de los métodos, y en la parte final del ensayo las relacionaremos al tema de la justicia global, abordado en Frontiers of Justice. Analizo el discurso del cosmopolitismo ético de Nussbaum en términos de sus presunciones psicológicas, filosóficas y sociológicas, de la metodología de la abstracción, de los públicos a los que se dirige implícitamente y de las metas programáticas y estrategia subyacente de cambio social. Concluyo que para este tópico de cosmopolitismo y justicia global, los métodos de Nussbaum son en cierta manera insuficientes y requieren ser complementados en mayor medida desde las ciencias sociales ${ }^{3}$.

\section{MÚLTIPLES TAREAS Y MÚLTIPLES MÉTODOS}

\section{Requerimientos de un programa de investigación y de políticas para el desarrollo humano}

Una teoría del desarrollo humano necesita ser más que una teoría de la economía del bienestar o una teoría ética. El enfoque de capabilities de Amartya Sen surgió en respuesta a la pregunta de cuál es el espacio adecuado para evaluar las ventajas de la gente y la distribución de esas ventajas (“iigualdad de qué?”). Pero una teoría o enfoque del desarrollo humano tiene propósitos adicionales a la evaluación y requiere otros tipos adicionales de información. Sen ha ampliado considerablemente su enfoque de capabilities a lo largo de los años, notoriamente en Development as Freedom (2000) ${ }^{4}$, aunque todavía conserva un sello de economía del bienestar. Una teoría del desarrollo humano debería preferentemente ser útil $-\mathrm{y}$ al menos no engañosa - en otros papeles también: para entender la conducta y para explicar la capacidad de actuar (agency) y las satisfacciones; para movilizar la atención, el interés y el compromiso; y para orientarnos en los procesos de formular y realizar decisiones, exigentes no sólo intelectualmente, sino también psíquica y emocionalmente. El enfoque de capabilities de Martha Nussbaum aborda esos diversos propósitos vitales, y no se reduce a la evaluación de ventajas y su distribución. Su trabajo reciente fortalece ampliamente su contribución en esas áreas, si bien conserva algunos rasgos problemáticos.

Tres áreas de trabajo sobre el desarrollo humano reciben mucha atención: cuáles son los valores éticos que de-

\footnotetext{
${ }^{3}$ El presente ensayo utiliza y extiende ideas de dos artículos anteriores: Gasper, 2003, 2006.

${ }^{4}$ Hay traducción al castellano: Desarrollo como libertad, Planeta, Madrid, 2000. [Nota del traductor.]
} 
Cuadro 1. Áreas esenciales en el trabajo sobre desarrollo humano

\begin{tabular}{|c|c|}
\hline Áreas muy discutidas & Áreas complementarias vitales \\
\hline $\begin{array}{l}\text { I. Conocimiento positivo sobre: a) causas; b) requisitos; } \\
\text { c) restricciones; d) efectos. }\end{array}$ & IV. Riqueza de observación y evidencia. \\
\hline II. Teoría ética. & $\begin{array}{l}\text { V. Movilización y mantenimiento de interés y compromiso público y } \\
\text { privado. }\end{array}$ \\
\hline $\begin{array}{l}\text { III. "Puesta en práctica": a) medición; b) prioridades; } \\
\text { c) implementación; d) institucionalización }\end{array}$ & $\begin{array}{l}\text { VI. Estimulación y mantenimiento de un programa de investigación y } \\
\text { política: a) una red cooperativa de investigadores y usuarios, con } \\
\text { recursos y espíritu de equipo, apoyada por: b) estrategia y tácticas } \\
\text { juiciosas. }\end{array}$ \\
\hline
\end{tabular}

ben definir y conducir el desarrollo humano; cuáles son las causas y los obstáculos para el desarrollo humano; y cómo podemos hacer operativo un enfoque teórico (un conjunto de valores, conceptos y teorías predictivas), en términos de mediciones, instituciones, instrumentos, procedimientos y prioridades de política. Como se sugiere en el cuadro 1 , existen tres áreas complementarias de trabajo, menos discutidas pero de principal importancia. La institucionalización y, por tanto, la operación tienen que cubrir no solamente los requerimientos de la prestación de servicios, sino también la necesidad de establecer y mantener un programa de investigación y de acción, que incluye la integración y el mantenimiento del apoyo de un cuerpo de investigadores y usuarios potenciales. Aún más, tener en marcha un programa de investigación y de política del desarrollo humano, y actuar sobre sus hallazgos, requiere de una base de amplio compromiso e interés públicos. Por último, sin una abundante observación y evidencia, cada uno de los requerimientos — compromiso, interés, teoría ética y teoría positivaparece débil e insuficiente. Repasaremos cada una de estas seis importantes áreas.

Una cualidad especial de Nussbaum es su visión integral del desarrollo humano, que atiende todas o casi todas esas áreas interconectadas. En algunas, sin embargo, sus métodos retóricos han mostrado debilidades y no sólo fortalezas. Por ejemplo, para integrar y mantener el apoyo de colaboradores y usuarios potenciales hay mucho que aprender de los métodos de Sen para la conducción de investigaciones, los cuales contribuyen a su habilidad para movilizar colaboradores e influir en distintas redes de investigación y de desarrollo de políticas. Sen se preocupa por encontrar las posiciones en común para cons- truir y preservar un carácter convincente que aliente a los otros y para colaborar y dirigir el trabajo en conjunto (véase Gasper, 2000).

\section{Diversas etapas en el discurso ético/práctico requieren distintos métodos}

Mientras más tipos de propósitos tengamos, más tipos de evidencia, conceptualización y teorización debemos utilizar. El trabajo de Nussbaum está inspirado en el principio general de que los discursos ético y práctico incluyen una diversidad de actividades, las cuales tienen propósitos definidos y diferentes métodos adecuados. Esto proporciona a su trabajo inusual riqueza y penetración perceptiva (insight). Su enfoque de capabilities involucra mucho más que una lista de prioridades específicas para las vidas humanas. En una descripción preliminar se puede decir que éste involucra también:

- Una amplia pero focalizada visión, que atiende al contenido y las potencialidades en aspectos clave de las vidas de la gente, de las vidas de toda la gente. Su lista de capabilities prioritarias es parte de esto.

- Una manera de percibir, con apertura y afinidad (sympathy).

- La utilización de una gama de evidencias más amplia, incluyendo fuentes más ricas - ficción, poesía, autobiografías, y ahora también entrevistas y observación con fines abiertos (open-ended) — que las utilizadas en economía y en muchos otros trabajos sobre niveles de vida. - Una comprensión más profunda, que usa ricas imágenes de la mente, del concepto de persona, de las emo- 
ciones y del lenguaje; y un estilo de presentación más rico, que busca explorar el contenido humano de esa evidencia, incluyendo su contenido emocional, para provocar interés tanto por las personas como por aspectos particulares de la vida.

¿Debería incluirse todo esto cuando consideramos el enfoque de capabilities de Nussbaum? Sí, ya que nos interesa conocer todos los componentes operativos esenciales, no sólo uno, de su enfoque de la ética del desarrollo humano. Aún más, podemos apreciar vinculaciones entre este conjunto de componentes, no una simple lista de capabilities prioritarias por un lado y por otro un racimo de rasgos no relacionados. Especificar y discutir su enfoque de capabilities prescindiendo de estos otros componentes resulta artificial y puede conducir a conclusiones erróneas.

Así, "enfoque de capabilities" resulta un título imperfecto para esta perspectiva integral del desarrollo humano. "Enfoque de capabilities" fue una descripción correcta de la propuesta de Sen para la economía del bienestar: adoptar un espacio primario diferente para dar cuenta del bienestar o la ventaja, una alternativa a la utilidad o al ingreso real. Sen ha utilizado otros membretes cuando amplía su trabajo más allá de la explicación del bienestar: "desarrollo como libertad" o, en algunas ocasiones, el "desarrollo humano" del Programa de Naciones Unidas para el Desarrollo (PNUD). Nussbaum utilizó la etiqueta "democracia social aristotélica" en sus trabajos anteriores, pero ya ha rebasado eso. "Humanismo cosmopolita" podría ser adecuado ahora, con el "enfoque de capabilities", como una etiqueta secundaria para indicar la perspectiva desagregada sobre las vidas de las personas y el respeto a sus libertades. O podemos concentrarnos en lo que el enfoque busca y hablar de su enfoque de la ética del desarrollo humano. Comparado con el enfoque de Sen, Nussbaum tiene una orientación menos planificadora y más inclinada a proyectar principios constitucionales básicos, como se aprecia en Poetic Justice (1995) y Cultivating Humanity (1997) ${ }^{5}$. Aquí, sin em-

\footnotetext{
${ }^{5}$ Hay traducción de ambas obras al español, ambas de la editorial An-
}

bargo, justo como Alkire (2002) utiliza la etiqueta "enfoque de capabilities" para referirse a todo el sistema de Sen, en lo que a mí respecta, algunas veces me referiré al enfoque integral de Nussbaum, por falta de una alternativa más precisa a la mano, como su "enfoque de capabilities".

\section{La evolución de la ética del desarrollo humano de Nussbaum}

Un programa de investigación conducido por Sen y Nussbaum en los últimos años de la década de 1980 y primeros de la de 1990, en el seno del Instituto Mundial para la Investigación de la Economía del Desarrollo (WIDER, por sus siglas en inglés) de la Universidad de las Naciones Unidas, produjo dos notables volúmenes, The Quality of Life (Nussbaum y Sen, 1993) ${ }^{6}$ y Women, Culture and Development (Nussbaum y Glover, 1995). Estos libros consolidaron y ampliaron ideas sobre qué deberíamos entender por mejora en la vida de una persona o grupo, $y$ en qué medida las respuestas a tales cuestiones son culturalmente relativas. Nussbaum y Sen han adoptado posiciones un tanto diferentes. Comparado con el enfoque más 'delgado', más kantiano de Sen, la ética neoaristotélica de las capabilities de Nussbaum ha proporcionado una rica imagen de lo que es una vida humana plena. Esta ética habla en términos de gente real, vida real, más que de abstracciones remotas; y puede por eso llegar a más amplias o diferentes gamas de personas que los economistas y los filósofos analíticos. Al mismo tiempo, inclusive entre aquellos que percibieron tales fortalezas o potenciales, los trabajos de Nussbaum de ese periodo (notablemente Nussbaum, 1988, 1992, 1993; Nussbaum y Glover, 1995) generaron recelos considerables: “[un] estilo aristotélico todavía demasiado disciplinario y enfático puede acarrear no sólo substantivas deficiencias intelectuales, sino enemistarse con otros y así hacer cor-

drés Bello, Barcelona: Justicia poética, 1997, y El cultivo de la humanidad, 2000. [Nota del traductor.]

${ }^{6}$ Hay traducción al español: La calidad de vida, Fondo de Cultura Económica, México, 1997. [Nota del traductor.] 
to circuito en el debate que se buscaba desarrollar" (Gasper, 1997: 300).

El trabajo subsecuente de Nussbaum, notoriamente en Women and Human Development (2000a) ${ }^{7}$ y Frontiers of Justice, ha enfrentado los retos manifestados por muchos comentaristas. Estos trabajos ofrecen una presentación integrada y práctica, más profunda y más mesurada que sus trabajos anteriores sobre desarrollo humano, los cuales ella correctamente declara ahora reemplazados (por ejemplo, 2000b: 103). Importantes áreas nuevas de exposición y pensamiento son evidentes: desde el duro razonamiento práctico del derecho, particularmente desde su cambio parcial de un departamento de clásicos a una escuela de derecho; su adopción del liberalismo político rawlsiano, que proporciona espacios para diversas concepciones exhaustivas de la ética, más que tratar de imponer una en particular; y, quizás de manera más importante, sus visitas periódicas de investigación a la India, incluyendo intensos recorridos de campo a finales de la década de 1990 y el considerable estudio asociado.

Nussbaum incorpora ahora percepciones del comunitarismo, pero logra evadir el relativismo; y demuestra con mayor detalle, tanto en teoría como en casos concretos, cómo hay posibilidades para la variación cultural, la flexibilidad y la sensibilidad contextual al poner en operación las capabilities centrales estipuladas, y en la vida más allá de ellas. Hace notar una serie de canales importantes para esto (2000b: 132; 2006: 78-80, 256-257): 1) estipular solamente un limitado conjunto esencial de $c a-$ pabilities prioritarias, más allá de las cuales puede haber diversidad; 2) incluir en el conjunto esencial libertades y posibilidades de elección; 3) establecer esas prioridades sólo en términos generales y 4) por lo que deben ser operacionalizadas mediante procesos democráticos locales; y 5) establecerlas en términos de asegurar capabilities (como oportunidades), más que insistir en los correspondientes functionings ${ }^{8}$. El canal 1 marca el alejamiento de

\footnotetext{
${ }^{7}$ Hay traducción al español: Las mujeres y el desarrollo humano: el enfoque de las capacidades, Herder, Barcelona, 2000. [Nota del coordinador del número, Julio Boltvinik.]

${ }^{8}$ Por las mismas razones que, como se argumentó en la nota 1 no se ha traducido en este número el término capabilities, tampoco se tradu-
}

Nussbaum de su anterior defensa de políticas públicas basadas en una ética más extensiva y, en particular, más individualista.

Otra profundización del enfoque, al menos para algunos ojos, en términos tanto de argumentación como de tono, es la larga y amable repuesta de Nussbaum a la crítica de que las aspiraciones espirituales y religiosas eran desdeñadas en sus explicaciones anteriores de las capabilities centrales (véase, por ejemplo, Alkire y Black, 1997). La religión es destacada como una respuesta legítima a las necesidades de expresión, asociación y afiliación (2001a: 419). Nussbaum conserva límites, basados en principios, al "libre" ejercicio de la religión: no ha de estar libre de razón, consistencia y humanidad.

Nussbaum deja así claro su apoyo a un liberalismo político más que a uno exhaustivo, y su apoyo a un modelo de "consenso traslapado" (como argumentaron muchos teóricos de las necesidades básicas; véase Braybrooke, 1987; Gasper, 1996a, 2004). Ahora busca especificar los criterios de "un mínimo social decente" (2000a: 75) más que una lista exhaustiva de requerimientos sugeridos para el florecimiento humano, y con base en un conjunto limitado de capabilities más básicas, en contraste con una más larga lista de functionings requeridos propuestos. En su versión de principios de la década de 1990 había propuesto criterios para, en primer lugar, una vida considerada "humana" $y$, en segundo lugar, una vida considerada una buena vida humana. La versión más reciente contiene un enfoque intermedio más útil, como le aconsejaron varios comentaristas. De manera similar, el sentimiento fuertemente aristotélico, combativo, del norte, ha declinado considerablemente. Su autodesignación como aristotélica ha desaparecido, lo que refleja una conciencia acerca de sus otras afiliaciones, nuevas y viejas, incluyendo la Ilustración y sus objetivos de libertad y "una vida iluminada por el uso crítico de la razón” (1999b: 2).

Mientras que Nussbaum y Sen se abren los dos de manera impresionante a un conjunto de roles, desde revisar la experiencia, construir marcos teóricos, hasta ela-

ce el de functionings. En la obra de Sen se establece una relación entre ambos similar a la de potencia y acto. [Nota del coordinador del número, Julio Boltvinik.] 
borar propuestas de acción, Nussbaum parece más consciente de los roles adicionales de crear compromiso, interés y motivación. Para cuestionar el consumismo en los países ricos, su enfoque también ofrece más. En correspondencia con sus diferentes concepciones de público, individualidad y roles (para una comparación más completa sobre estas líneas, véase Gasper, 2003), Nussbaum utiliza una diferente "paleta" metodológica, más amplia y más rica.

\section{¿Por qué una lista?}

Antes de que veamos con más amplitud los roles y métodos, enfoquémonos en el tema más familiar de la lista de capabilities prioritarias de Nussbaum y veamos cómo ésta también debe ser entendida como un método y en términos de sus roles subyacentes. El ejercicio de construcción teórica de Nussbaum se dirige a identificar una lista ampliamente consensuada o convincente de capabilities (oportunidades) de prioridad universal. ¿̨or qué?

Nussbaum advierte que la lista está permanentemente abierta al debate y a la reelaboración, así como a la interpretación local y al establecimiento de umbrales — por ejemplo, los umbrales son "establecidos por los procesos políticos internos en cada nación, frecuentemente con la aportación de un proceso de revisión judicial" (2001a: 418). Entonces, ¿por qué tratar de especificar personalmente una lista como esa? La respuesta parece ser que sin un conjunto de prioridades esenciales arraigadas dejamos el asunto demasiado abierto a la interpretación por parte de los que detentan el poder, además de que Nussbaum busca comunicar un método de pensamiento, incluyendo principios de procedimiento y selección, para desarrollar tal conjunto de prioridades. Más que un ejercicio monológico de gobierno elitista, una lista así proporcionaría un punto de partida y fundamento para una carta de derechos, como parte de una constitución legal.

Su lista destaca capacidades y oportunidades para elegir. Algunos críticos sugieren que no es liberal insistir en que las personas deben poseer posibilidades de escoger y las capacidades para hacerlo. Pero la posibilidad de escoger incluye la opción de escoger un modo de vida que no permite escoger (en una orden religiosa, por ejemplo). Nussbaum proporciona ejemplos de mujeres bien educadas que escogen utilizar una burka (velo que les cubre el rostro), aunque no están obligadas a hacerlo, y algunas que eligen esa opción después de un tiempo viviendo sin ese velo, y señala que ellas no insisten en que las otras debieran ser privadas de esa misma decisión y ser obligadas a usarlo (por ejemplo, 2000 a: 153). De la misma manera, da ilustrativos ejemplos de personas que festejan un campo más extendido de elecciones, por ejemplo, gracias a la alfabetización.

¿Tienen estas visiones y prioridades propuestas por Nussbaum realmente un consenso amplio? Mientras Martha Nussbaum es sorprendentemente optimista acerca de los impactos de la opresión sobre las preferencias y la aceptación (por ejemplo, "los regímenes que fracasan en otorgar salud, o seguridad básica o libertad, son inestables", afirma; 2000a: 155), las prioridades ciertamente parecen compatibles con el gigantesco estudio Voices of the Poor (Narayan et al., 2000) ${ }^{9}$. Su lista, en todo caso, no descansa sobre encuestas de opinión actuales sino en un criterio propuesto de priorización y en la expectativa de que sus resultados convergerán con los de un criterio de deseo informado.

Mientras Nussbaum aplica cuidadosamente un criterio - iqué constituye una vida humana decente?-, éste permanece un tanto vago y su aplicación, intuitiva. Su preferencia por la cantidad mosaica de diez hace que la lista resultante aparezca un poco artificiosa. En contraste, Doyal y Gough en A Theory of Human Need (1991) ${ }^{10}$ utilizan criterios más precisos: primero, ¿¿uáles son los prerrequisitos para una salud física y mental y para la autonomía de la actuación?; y segundo, ¿̨uáles son los prerrequisitos para niveles más elevados de florecimiento, incluyendo autonomía crítica? Aún más, éstos contienen un método de aplicación más explícito y estructurado, que opera hacia atrás a lo largo de una cadena causal, desde los functionings deseables a las capabilities requeri-

\footnotetext{
${ }^{9}$ Hay traducción al español: La voz de los pobres. ¿Hay alguien que nos escuche?, Mundi-Prensa, Madrid, 2000. [Nota del coordinador del número, Julio Boltvinik.]

${ }^{10}$ Hay traducción al español: Teoría de las necesidades humanas, FUHEM, Icaria, Madrid, 1994. [Nota del traductor.]
} 
das, a las características de los bienes, a los satisfactores específicos, a las precondiciones sociales implicadas (véase también Gough, 2000, 2003; Gasper, 2004). Nussbaum carece de esta estructura y así su lista deviene en una selección un tanto personal de prioridades a lo largo de varios de estos niveles.

Nussbaum considera el caso de los religiosos célibes, quienes parecen rechazar que "resulta siempre racional querer [todas las capabilities humanas esenciales especificadas] independientemente de cualquier otra cosa que uno quiera"; y argumenta que ellos racionalmente desean las oportunidades sexuales y de otro tipo cuyo uso rechazan en los hechos, pues es solamente así que su abstinencia sexual y de otros tipos adquiere significado (2000a: 88). Muchos ermitaños difieren. Nussbaum argumenta que los ermitaños buscan afiliaciones con los demás (2000a: 92) por medio de rezar por otros o, indirectamente, de promover la elevación espiritual universal. De hecho, algunos ermitaños no buscan afiliación social, ni mejora humana, sólo una afiliación con alguna noción de lo divino.

A Nussbaum se le presentan aquí dos caminos a seguir, no mutuamente excluyentes. Puede tomar el camino principal seguido por Doyal y Gough: establecer y promover las necesidades implicadas en un criterio normativo más restringido y más preciso. En tal caso puede dejar de insistir en que los ermitaños le otorgan prioridad a las oportunidades sexuales. En segundo lugar, si desea, en cambio, o también, trabajar el más amplio y vago criterio de la decencia humana - menos amplio y vago que el de la "buena vida", criterio que presentó en su trabajo anterior de comienzos de la década de 1990, aunque no tan desarrollado como para dar una pulcra lista de diez puntos-, entonces la teoría requiere especificaciones más borrosas (fuzzy). Nussbaum ya identifica dos de las capabilities centrales — afiliación y razón práctica- como más centrales que otras; así, comparativamente, pueden presentarse algunos casos marginales y la lista no tendría un punto final preciso. Algunas de las capabilities propuestas pueden ser vistas mejor como un conjunto de elementos deseables importantes que como requerimientos absolutos (Crocker, 1955; Gasper, 1997). En esta segunda opción, la lista puede ser presentada co-

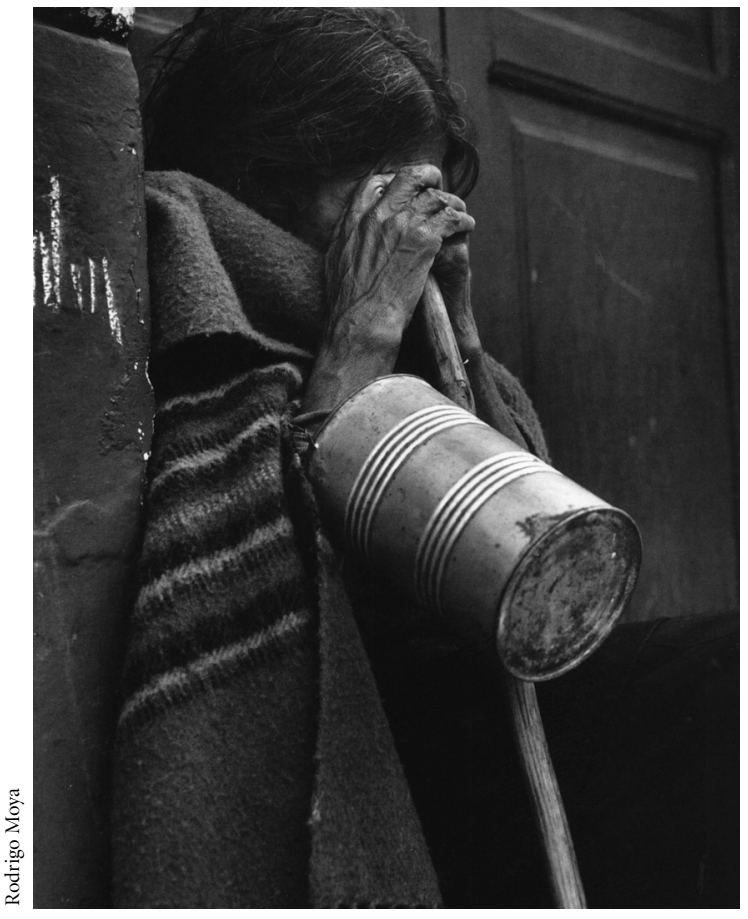

Quito, Ecuador, ca. 1965.

mo una ilustración de una metodología que ofrece un marco de referencia para la investigación dialógica y la especificación práctica (véase Alkire y Black, 1997; Alkire, 2002). De otra manera, la lista despierta temores en algunas personas de un intento preventivo por capturar la atención de los que tienen el poder en las grandes metrópolis. La tradición internacional de los derechos humanos y el movimiento de ética global de Hans Küng y otros ayudan a mostrar cómo una teoría borrosa puede incluso así guiar decisiones, estructurar áreas de debate en marcha, y respetar y enfrentar diferencias. Una lista debería ser teorizada y relativizada identificando y destacando los roles a los que se supone debe servir. La lista es un medio, no un fin; si nos enfocamos a los fines podemos encontrar medios alternativos, suplementarios o modificados que sean adecuados. Los elementos valiosos del enfoque integral de capabilities no deberían ser puestos en peligro por la reducción del enfoque a una búsqueda de una especificación perfecta de este elemento indicativo. 
Así, el trabajo de Nussbaum puede ser visto como justificación de una carta de derechos, pero es menos riguroso y elaborado que el trabajo paralelo de Doyal y Gough, el cual corrobora pero también actualiza el enfoque detrás de su lista. ¿Por qué entonces ha tenido el trabajo de Nussbaum más atención e impacto? En parte porque Nussbaum incorpora con más fuerza sus medios de priorización en un amplio proyecto humanístico. Aunque sus métodos de priorización pueden ser burdos, veremos que posee métodos adicionales que se dirigen a muchos otros aspectos que requerimos en la ética del desarrollo humano.

\section{Cosmopolitismo}

El cosmopolitismo - la idea de que los principios de la justicia humana y la ética se aplican con alcance global- ha sido un tema clave en el trabajo de Nussbaum. For Love of Country (Nussbaum et al., 1996) ${ }^{11}$ criticó el desequilibrado patriotismo en Estados Unidos, así como otro factor contribuyente: la ignorancia acerca de la mayor parte del resto del mundo. Cultivating Humanity (1997) analiza una respuesta al problema anterior: la educación innovadora en las universidades estadounidenses acerca de la diversidad y de las diferencias — globales, de género y raciales-, con la inclusión de un capítulo intitulado "Ciudadanos del mundo". Su nuevo libro Frontiers of Justice, basado en su serie de Conferencias Tanner "Beyond the Social Contract" (Más allá del contrato social), argumenta que existen debilidades básicas en el enfoque del contrato social, como el de John Rawls, porque marginan o ignoran a los discapacitados, al no humano y al débil. Nussbaum discute detalladamente esta última preocupación con referencia a los pobres de todo el mundo, creando así una perspectiva cosmopolita:

Si nuestro mundo ha de ser un mundo decente en el futuro, debemos reconocer desde ahora que somos ciudadanos de un mundo interdependiente, que se man-

11 Hay traducción al español: Los límites del patriotismo, Paidós Ibérica, Barcelona, 1999. [Nota del traductor.] tiene unido por fraternidad mutua, así como por la búsqueda de ventajas mutuas, por compasión e interés propio, por el amor a la dignidad humana en toda la gente, aun cuando no obtengamos beneficio alguno por cooperar con ellos. O más bien, aun cuando lo que tenemos que ganar es la mayor de todas las cosas: la participación en un mundo justo y moralmente decente (Nussbaum, 2006: 324).

Aquí consideramos el cosmopolitismo ético, las visiones de que uno podría relacionarse éticamente con las personas alrededor del mundo como compañeros humanos iguales. Debemos distinguirlo de otros tres conceptos. El cosmopolitismo político compete a los sistemas de poder y autoridad: "una teoría del gobierno del mundo y la ciudadanía correspondiente” (Brennan, 2001: 76). El cosmopolitismo cultural involucra "un entusiasmo por las diferencias de costumbres, pero como material ético o estético para una cultura policroma unificada" (ibid.). El cosmopolitismo sociológico se refiere a altos niveles de movilidad, exposición y adopción interculturales.

Nussbaum es defensora de un cosmopolitismo ético que consiste en un trato igualitario a las personas de todo el mundo en muchos aspectos (universalismo), así como en obligaciones éticas sustantivas más allá de las fronteras nacionales (solidaridad), pero no de un gobierno mundial. Al contrario de lo que algunos temen, no es una cosmopolita política sino, en los términos de Timothy Brennan, sobre todo una internacionalista, "que no se riñe con los principios de la soberanía nacional, pues no hay otra vía en las condiciones modernas para asegurar respeto por las sociedades o pueblos más débiles" (2001: 77). Los principios éticos que defiende tienen el carácter de recomendaciones, con unas pocas excepciones normales (por ejemplo, que el genocidio justifica la intervención internacional).

No todas las visiones universalistas son solidarias. Lee Harris (2003) sugiere que Diógenes, creador del término cosmopolita, era un cínico con poco interés en los demás. En la concepción de Harris, la famosa frase de Diógenes de que él era un ciudadano del mundo era una broma. Diógenes pudo haber sostenido consistentemente que no reclamaba para sí mismo derechos diferentes que para cualquier otro — solamente uno, el derecho a ser dejado 
en paz. Marc Rich, el especulador internacional y tramposo en los mercados, reclama para sí mismo los mismos derechos que para todos: el derecho a comprar cualquier cosa que algún otro esté dispuesto a vender $\mathrm{y}$ a vender cualquier cosa que otro quiera comprar (tal como el petróleo a Sudáfrica durante el periodo del apartheid, e incluso quizás un veredicto legal o un órgano humano). Rich se autodeclara "un ciudadano del mundo" (citado en Gasper, 2005: 19).

La membresía de una comunidad moral global puede entonces interpretarse con varias concepciones. Nussbaum adopta lo que Charles Beitz (1999) denomina “cosmopolitismo liberal [ético]", en el que los miembros son personas individuales, no sociedades como ocurre en el "cosmopolitismo social [ético]". Rawls se sitúa más cerca de este último campo. Ambas posiciones contras$\tan$ con aquellas que conciben que las relaciones internacionales están más allá de la esfera de la moralidad. Al interior del "cosmopolitismo liberal" en sí mismo no todas las variantes son liberadoras; por ejemplo, cuando los principios de la moral global son las leyes del libre mercado. Brennan advierte que el neoliberalismo es el núcleo de la más poderosa comunidad cosmopolita global de hoy día.

\section{El proyecto cosmopolita de Nussbaum en Frontiers of Justice}

El cosmopolitismo ético de Nussbaum no es nuevo en sí mismo. ¿Qué añade Frontiers of Justice a la teoría cosmopolita? ${ }^{2}$ Primero, el tema unificador del libro es la incapacidad de la teoría del contrato social para proporcionar justicia a los grupos más débiles, aun en su más evolucionada versión kantiana: la teoría de la justicia de John Rawls. Frontiers of Justice es una crítica audaz del trabajo del tal vez más destacado filósofo político de finales del siglo XX, el líder de su revitalización intelectual. La filosofía política teórica y la ética social fueron áreas desa-

${ }^{12}$ Nussbaum elabora una lista de aspectos novedosos del libro en su conjunto en la p. 7 de Frontiers of Justice. lentadas hacia la mitad del siglo anterior, abrumadas por las enormidades de la historia del siglo XX, eclipsadas por los alcances y normas de las ciencias naturales, y sin embargo, protegidas de presiones en los países ricos occidentales por sus arreglos sociopolíticos de la posguerra. En el momento en el que esos arreglos de la posguerra empezaron a fracturarse, A Theory of Justice de Rawls (1971) resucitó y transformó el terreno intelectual en una extraordinaria hazaña de reflexión sostenida que abarcó numerosos temas importantes de una manera integrada. Sus cualidades, más las fracturas de opinión, alimentaron un explosivo resurgimiento de la filosofía política normativa. Rawls revigorizó la teoría de la justicia basada en el contrato social, enmarcándola de tal manera que los presuntos negociadores pensaran más ampliamente que en el interés personal y el contrato pudiera entonces ser considerado justo. En su postulada "posición original", el contexto para establecer un contrato social justo, los negociadores no saben cuál será su propia identidad social. Se asume, por tanto, que mostrarán un interés prudencial por la posición de los menos aventajados en la sociedad cuyas reglas ahora establecen.

La teoría de la justicia de Rawls funciona con una serie de fronteras. Primero hay una frontera intrasocietal que separa el dominio público, la esfera de la justicia social, del mundo privado de la familia. Esta presunción fue cuestionada por filósofas feministas, encabezadas por Susan Moller Okin. También están excluidos, en segundo lugar, los mentalmente discapacitados y, en tercer lugar, los animales no humanos. Por último, la teoría sigue siendo intranacional. Para Rawls, la justicia internacional era asunto de un contrato justo entre países, no un asunto a nivel de personas. Reconoció una virtud en la caridad para ayudar a los individuos desposeídos internacionalmente, pero no la aceptó como un deber de la justicia y en cambio desarrolló una teoría de las relaciones entre países (o, en sus términos, "pueblos").

Estas tres últimas fronteras son abordadas por Nussbaum en Frontiers of Justice. Su título se refiere tanto a las supuestas fronteras a la justicia como a las fronteras de la teoría y el debate. Así como las feministas han declarado que la familia es política y un campo para la justicia, Nussbaum declara que la esfera para la justicia se extien- 


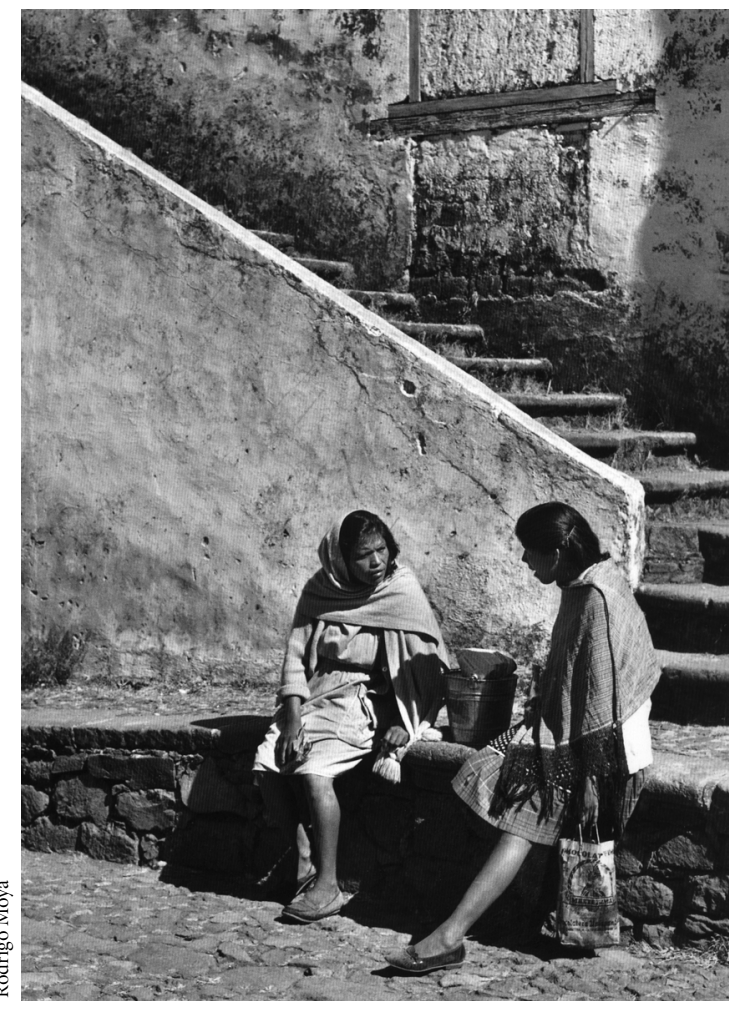

Casa de los Once Patios, Pátzcuaro, Michoacán, 1969.

de también en las otras tres direcciones. Me concentraré en la tercera: justicia internacional. Nussbaum sostiene que incluso variantes del contractualismo, como las de Beitz y Pogge, que visualizan el mundo como un dominio moral único, pero que conservan la perspectiva del contrato social de Rawls, no son suficientes para pensar acerca de la justicia porque las relaciones involucradas no pueden ser correctamente concebidas en términos de contratos entre negociadores aceptablemente iguales.

La primera novedad clave del libro es, entonces, su crítica sistemática de la teoría del contrato social (TCS). La segunda, y muy significativa para el cosmopolitismo, el libro representa una afiliación categórica al enfoque de derechos humanos y la oferta de unas bases para un planteamiento al respecto. La tercera consiste en que proporciona una exposición más clara que las previas del cambio de Nussbaum, siguiendo a Rawls, a un "liberalismo político" y de la aplicación directa de éste a una escala global. En cuarto lugar, hace sugerencias programáticas; Nussbaum tiene muy claro que aquí es donde los filósofos deben ceder el terreno a otras disciplinas (Nussbaum, 2006: 307).

Primero, la TCS, aun en la(s) versión(es) de Rawls, una vez que la probamos más allá de su territorio original del ajuste mutuo de un conjunto de contratantes egoístas y capaces, es considerada inferior a los enfoques de capabilities o de derechos naturales; por ejemplo, cuando la aplicamos a un escenario mundial de enormes desigualdades de poder. Frontiers of Justice contiene análisis considerables de los derechos de los discapacitados, de la pobreza global y de los animales, pero no de los niños. Inclusive en su territorio original, los supuestos de la TCS resultan problemáticos: que los contratantes regulan solamente para ellos mismos, no para otros (o se considera que representan adecuadamente los intereses de esos otros); que valoran únicamente sus propios intereses y ventajas, no los de los otros, y que están unidos en mutua indiferencia. La justificación metodológica convencional para tales supuestos, que se sabe son poco realistas, es que si un orden justo puede encontrarse inclusive en el puro interés propio, entonces podemos confiar verdaderamente en su sustentabilidad. Nussbaum rechaza esta postura: "no podemos asumir con seguridad que si de la prudencia derivamos los principios $\mathrm{X}, \mathrm{Y}$ y Z, entonces un punto de partida moralmente más rico nos dará X, Y y Z, y algo más que eso, pues el punto de partida moralmente más rico puede en realidad sembrar duda sobre $\mathrm{X}$ o $\mathrm{Y}$, o sugerir una manera totalmente distinta de pensar acerca de la sociedad" (2006: 56). Nussbaum arguye, siguiendo a Grotius e indirectamente a los estoicos, que no hay una buena razón para excluir la motivación humana básica de compañerismo con otros (fellowship) de la formulación de los principios fundamentales que moldearán una teoría de la justicia (2006: 37). En el contexto internacional, los supuestos utilizados en la TCS se vuelven todavía más problemáticos: que los únicos agentes morales importantes son países (o, en el Rawls tardío, "pueblos", los cuales están fuertemente unidos entre sí por afinidades comunes); y que estos países están aislados, son autosuficientes y casi iguales (2006: 231 ss.). 
Así, esta primera característica prominente de Frontiers of Justice involucra como visión central una teoría filosófica, la teoría del contrato social de Rawls, a la que encuentra deficiente en términos de capacidad para manejar tres problemas básicos de la ética — discapacidad, justicia internacional y derechos de los animales. Es juzgada como deficiente a partir de la consideración de nuestras intuiciones éticas y, por tanto, en términos del criterio de equilibrio reflexivo. En particular, la teoría de justicia internacional de Rawls soslaya la inviolabilidad de cada persona, un aspecto clave para la teoría doméstica de Rawls (Nussbaum, 2006: 253). Esta visión, en primera instancia filosófica, conduce a un discurso que sigue siendo moldeado por Rawls, al tiempo que intenta rebasarlo poco a poco. Este discurso aparece dirigido en primer término a los rawlsianos y escuelas filosóficas similares, y no puede alejarse mucho de su conjunto de supuestos porque corre el riesgo de perder a su público.

En segundo lugar, Frontiers of Justice deja más claro que "el enfoque de capabilities es una de las especies del enfoque de derechos humanos" (2006: 7; véase también $78,284)$, y que éste se fundamenta en la tradición de la "ley natural" de Grotius ${ }^{13}$. Requerimos "una concepción del propósito de la cooperación social que se centre en el compañerismo, así como en la la ventaja mutua" (2006: 227). En otra parte, "el respeto humano" es añadido a "compañerismo humano" (2006: 270), y en general Frontiers of Justice habla de dignidad humana. Una teoría apropiada de la justicia no surge simplemente de la negociación. El lenguaje de los derechos transmite adecuadamente la idea de "titularidades urgentes basadas en la justicia” (2006: 290).

Además de autoafiliarse, Frontiers of Justice subraya una base teórica para los derechos humanos internacionales, tema que ha sido abordado mediante un lenguaje peligrosamente oscuro. Los derechos humanos han de ser entendidos en su correspondencia con las necesidades fundamentales, a saber, los requisitos de una dignidad

\footnotetext{
${ }^{13}$ Hugo Grotius es considerado como el padre de la ley internacional moderna. En su On the Law of War and Peace (1625) argumentó en términos de principios éticos universales accesibles por medio de la razón.
}

básica, estipulada en la forma de un conjunto de capabilities (2006: 284 ss.). "Los derechos humanos son, en efecto, demandas justificadas referidas a tales capabilities u oportunidades básicas" (Nussbaum, 1999a: 87). Un derecho debe satisfacerse como una capability; no es suficiente que el derecho no sea activamente violado, su ejercicio debe existir como una posibilidad real. Con tal fundamento, los derechos pueden entonces, al contrario que en Onora O'Neil (1996), proveer un punto de partida más definitivo y básico que los deberes, pues cada noción de deber se deriva de una noción de necesidad o titularidad, y las necesidades básicas son más claras que los deberes para ayudar a su satisfacción (Nussbaum, 2006: 275 ss.). La especificidad de Nussbaum a propósito de los requisitos, y la limitación al logro de los umbrales básicos, también proporciona un fundamento más firme que la "perspectiva de libertad" de Sen y adicionalmente abre más espacio para que las personas busquen sus diversas concepciones del bien, no necesariamente la de la autonomía liberal (2006: 297).

Tercero, el Rawls tardío adoptó un "liberalismo político" que parte del reconocimiento de muchas concepciones exhaustivas de la vida que compiten entre sí y que deben tratarse con respeto. Rawls aplicó esto al ámbito interno de una nación. Así lo hace Nussbaum, desde los últimos años de la década de 1990, en su reformulación de su enfoque de capabilities como un formato para especificar los requisitos prioritarios para la dignidad hasta llegar a los "niveles de los umbrales", requisitos que forman un área de consenso necesariamente implicado entre las concepciones exhaustivas. Nussbaum, a diferencia de Rawls, extiende ahora su "liberalismo político" a una escala global (2006: 299 ss.) para respetar la dignidad y la inviolabilidad de cada persona. Esto todavía sigue estando lejos de una ética universal y de una concepción del florecimiento exhaustivas (2006: 75) pero, como apunta Nussbaum, la Declaración Universal de Derechos Humanos de 1948 fue precisamente un ejercicio de este tipo en liberalismo político. A través de su adherencia al movimiento de los derechos humanos, Nussbaum clarifica y fortalece su posición en la política del discurso ético. En tal contexto puede presentar su lista de capabilities requeridas menos enfáticamente. Ésta aparece, en- 
tonces, como una parte indicativa de un enfoque para pensar en los requisitos de la dignidad humana, los cuales serán utilizados en diferentes sentidos en distintos lugares y no como mandamientos grabados en piedra. Muchas naciones se comprometen con constituciones y cartas de derechos humanos, pero en cada caso de manera un tanto diferenciada y sujeta a evolución.

El cuarto aspecto digno de mención aquí en Frontiers of Justice es un conjunto de sugerencias sobre las políticas y la práctica internacionales. Más adelante será esquematizado en la sección "La política del cambio". Antes de ver con más detalle cómo Nussbaum se involucra con la esfera de la justicia global, consideremos los métodos que adopta para buscar una gama apropiadamente amplia de propósitos.

\section{ROLES Y MÉTODOS}

\section{Roles}

Un rol consciente del enfoque de capabilities de Sen ha sido: 1) aumentar la gama de tipos de información que utilizamos, a fin de proporcionar un informe evaluativo más adecuado. Recientemente Sen ha destacado un segundo rol: 2) proporcionar apuntalamientos para concepciones de derechos humanos. Nussbaum comparte estos propósitos y resalta también un gemelo democrático para el rol de manejar información más relevante: 3) proveer un lenguaje pertinente para expresar mejor de lo que lo hacen las mediciones de ingreso y utilidad las multifacéticas preocupaciones propias de la gente (2000b: 138-139). Se entiende que el informador evaluativo, y no solamente su información actual, puede ser afectado por la elección de lenguaje. Dos roles más del planteamiento de Nussbaum son, así: 4) hacer a los observadores más abiertos y enriquecer sus percepciones del contenido de las vidas; y como resultado se espera: 5) crear solidaridad y compromiso. "Ponerse en los zapatos de otras personas" con imaginación te puede cambiar a ti y no sólo a tu conjunto informativo.

Nussbaum - quien fue actriz en una etapa temprana de su carrera- es más consciente o explícita que Sen acerca de esos últimos roles. A diferencia de los supuestos y la influencia de muchas teorías económicas, Sen correctamente señala que la buena voluntad existe, aunque no examina cómo ésta puede ser promovida y defendida. Ha argumentado que la información pública en una democracia previene hambrunas, pero esto supone que a la mayoría informada le preocupa la minoría vulnerable o que teme sus reacciones. La simple provisión de información pública, de hecho, fracasa en muchos casos intranacionalmente y, por supuesto, internacionalmente. Una amplia base informativa y una abundante manera de presentarla pueden contribuir a la empatía, la capacidad para comprender los sentimientos de los demás; y a la simpatía, es decir, observar con interés y preocuparse por los demás. Sin embargo: "que la simpatía promueva la compasión entre propios y extraños [...] dependerá de nuestros juicios de gravedad, responsabilidad e interés adecuados" (Nussbaum, 2001a: 440). Que la compasión conduzca a acciones altruistas dependerá también de la voluntad y de las visiones acerca de las obligaciones transjurisdiccionales y de los respectivos roles de los diferentes organismos.

El lenguaje universalista de Nussbaum se centra en lo que compartimos como seres humanos: apunta a otorgar respeto a lo que merece respeto, no hacia características moralmente irrelevantes como raza, género o, se puede sostener, nacionalidad. Su modulado pero franco cosmopolitismo (Nussbaum, 1996, 2006), en el que sostiene círculos concéntricos de intensidad de afiliación decreciente, está vinculado con su método. Observar el contenido detallado de las vidas de las personas se considera una manera de fortalecer no sólo el reconocimiento de lo que compartimos más allá de detalles circunstanciales, sino también la aceptación emocional de esta humanidad compartida. Mientras que el enfoque central de Sen es el de un teórico, cuyo trabajo se enriquece de y enriquece a la vez la observación empírica y el análisis de políticas, la metodología de Nussbaum se centra en la reflexión detallada sobre casos del 'tamaño de la vida' que involucran de manera reconocible a personas reales, ya sea verdaderamente reales o creaciones literarias. La tradición aristotélica considera que ese tratamiento ampliado de casos fomenta el discernimiento ético (1999b: 8). Su trabajo 
en las tres etapas de observación, teorización y análisis de políticas es menos tripartito que el de Sen: la reflexión en torno a un caso a menudo abarca las tres. Los métodos de Nussabum incluyen análisis textual profundo - usualmente, pero no siempre, de obras de ficción — con todas las sorpresas y aprendizaje que esto puede generar.

Nussbaum defiende una manera de percibir abierta y llena de interés, una amplia pero focalizada visión que cubre aspectos claves de las vidas de la gente, y formas de entender y estilos de presentar más ricos para explorar el contenido humano de las evidencias, incluyendo su contenido emocional. Propone la empatía y enfatiza cómo ésta se vincula con la compasión. En todos estos aspectos, Nussbaum hace en gran medida lo que recomienda. Pero existen repetidas quejas a propósito de su conjunto de evidencias y de interlocutores, y su estilo de debate. Aquí consideraremos el conjunto de sus fuentes intelectuales y su grado de experiencia y colaboración de campo; su utilización de narrativas humanas muy ricas; su examen de la emoción clave de la compasión; y su estilo argumentativo.

\section{El conjunto de fuentes}

Sen, Nussbaum y los Informes sobre el Desarrollo Humano de las Naciones Unidas concluyen que no todas las cosas de gran importancia son conmensurables; ni cuando pensamos en la vida como un todo, ni aun cuando discutimos políticas públicas. Por consiguiente, necesitamos evaluar utilizando diversos conjuntos informativos. Nussbaum va más allá, puesto que a la evaluación añade propósitos de explicación y persuasión. Moviliza una gama de distintos tipos de materiales en adición a los convencionales en filosofía y economía: ficción, poesía, autobiografías, entrevistas y observación directa. Su antiguo e ilustrativo examen de literatura imaginativa - griega clásica, helénica, romana y europea modernase ha ampliado ahora para cubrir de manera menos exclusiva fuentes del norte, burguesas o de ficción. También deriva elementos de la ley y la psicología, y de manera meditada aborda las elecciones prácticas que tienen que encarar los jueces y los políticos, incluyendo cues- tiones de balance, factibilidad y coordinación de tiempos. Su trabajo posterior a 1994 se asocia entonces mucho más con diversas realidades modernas del sustento humano y de la política.

La extensión y calidad de la gama de interlocutores que uno tiene es una compensación potencial vital para los inevitables límites de la experiencia propia. Nussbaum disciplina sus ideas mediante casos contemporáneos y con base en las situaciones de gente común, no sólo a través de Proust, las tragedias griegas y Henry James, aunque el balance se inclina todavía en favor de la mezcla "intelectualoide del norte". Si bien ha añadido cobertura y algunos casos sustanciales modernos no europeos, en Women and Human Development éstos seguían siendo relativamente escasos y en el estilo de camafeos literarios, tomados con acierto algunas veces de la literatura (especialmente una historia de Rabindranath Tagore). Hizo también una utilización intensiva y buena de los casos de dos mujeres indias modernas - Vasanti en Ahmedabad, y Jayamma en Trivandrum. Con esos casos arranca el libro y son aludidos con frecuencia en sus últimas etapas. Aun así, son escasos en número y profundidad para el ambicioso propósito de Nussbaum, quien continúa, sin embargo, haciendo breves pero intensivos y regulares viajes de investigación a la India, que influyen fuertemente en su trabajo reciente. Los filósofos deben primariamente basarse en los estudios de campo desarrollados por otros —_ ¿cuál era la exposición al campo de Kant o de Rawls?” diría alguien a manera de defensados y sin una rica experiencia del planeta, surgen problemas de credibilidad e imagen para los filósofos sociales del desarrollo humano global. ¿Cuán confiablemente pueden interpretar lo que leen? El redescubrimiento de las conferencias de Kant sobre geografía mundial ha revelado sus grandes limitaciones al respecto. Nussbaum merece crédito por exponerse de manera más directa. A la edad de cincuenta años experimentó "días que fueron diferentes de cualquier día que yo hubiera vivido nunca" durante sus viajes de campo a la India (2000a: ix). El prefacio de Women and Human Development no considera debidamente el posible impacto de meses, $\mathrm{o}$ años, de experiencia, pero Nussbaum ahora regresa cada año a la India y se sumerge en la literatura y en los debates de ese país. 


\section{Comprensiones éticas a partir de las narraciones humanistas de densa textura}

En Poetic Justice (1995) ${ }^{14}$ Nussbaum argumenta:

[...] una novela como Tiempos difíciles [Hard Times, de Dickens] es un paradigma de tales evaluaciones [de calidad de vida de la gente basadas en las necesidades/ capabilities]. Al presentar la vida de una población con gran variedad de distinciones cualitativas y complejas descripciones individuales de functioning y de los impedimentos al functioning, utilizando una noción general de la necesidad humana y del functioning humano en un contexto sumamente concreto, proporciona el tipo de información que tales evaluaciones requieren, e involucra al lector en la tarea de hacer la evaluación (Nussbaum, 1998: 245).

Se considera que Tiermpos difíciles contiene tanto un rol crítico como uno constructivo. Trae a la vida, en la persona de Gradgrind, la estrecha perspectiva del pensamiento económico rutinario. Éste insiste en que todo lo importante puede ser medido, comparado y luego sumado en un simple cálculo que permite una nítida solución correcta; y más allá, que los motivos de las personas son simples también, y están basados únicamente en el interés personal. La novela refuta esta perspectiva a través de la historia propia de Gradgrind y la de su familia. Muestra que lo que es llamado "economía sofisticada" es una mala novela (1998: 233): narra historias equivocadas y es aceptable solamente cuando pone en claro que es un ejercicio reduccionista, planteado en términos de "si así...".

Constructivamente, novelas como Tiempos difíciles pueden hacer lo siguiente, argumenta Nussbaum:

- Muestran "un estilo de relaciones humanas en el que [...] las actitudes morales se vuelven más generosas por medio del juego de la imaginación" (1998: 234), contribuyendo así al hábito de tomar en cuenta que los otros "tienen una vida íntima compleja, en algunos sentidos misteriosa, en algunos sentidos análoga a la

${ }^{14}$ Hay traducción al español: Justicia poética, Andrés Bello, Barcelona, 1997. [Nota del traductor.] de uno mismo" (1998: 236). Este alcance más hondo contribuye a explicaciones más adecuadas y a mejores sociedades. La falta de tal acceso imaginativo a las mentes de los otros conlleva un "narcisismo psicológico", característico de ciudadanos que tienen dificultades para conectarse con otros seres humanos, conscientes de la importancia humana de los problemas involucrados (2001a: 426).

- Muestran la alegría y el valor de algunas cosas en sí mismas —incluyendo el juego y la diversión-, no meramente como cosas para usarse.

- Trascienden las fronteras entre culturas: "las obras de literatura imaginativa frecuentemente son [herramientas] más flexibles y versátiles para traspasar las fronteras culturales que los tratados filosóficos con sus términos del arte atados al tiempo y a la cultura, y su frecuente falta de compromiso con las esperanzas y temores comunes" (1998: 242).

- Promueven una perspectiva sobre "el ser humano" que puede ser compartida: un reconocimiento de "las necesidades humanas que trascienden fronteras de tiempo, lugar, clase, religión y etnia, y [convierten] en el centro de [nuestra] deliberación moral la cuestión de su adecuada satisfacción" (1998: 242); e incorporan, por ello, "ideales de la ilustración sobre la igualdad y la dignidad de toda vida humana, no del tradicionalismo ni del provincianismo" (1998: 243).

Algunos teóricos literarios argumentan que la literatura imaginativa es buena, de manera impar, en todo lo expuesto. "Ven la literatura [imaginativa] como un modo particular de pensamiento acerca del ser humano" (Haines, 1998: 21). Ella nos lleva a una variedad de otras mentes, por vías que otras modalidades difícilmente pueden hacerlo. El denso lenguaje de la literatura "expresa nuestras intuiciones morales de un modo en el que el lenguaje 'ligero' [de buena parte de la filosofía] no lo hace", argumenta Parker (1998: 10). Restringirnos al lenguaje ligero de la filosofía nos conduce de hecho a hablar acerca de otra cosa distinta de nuestros pensamientos morales. En reacción a las guerras religiosas en la Europa de los siglos XVI y XVII, la ética de la Ilustración escogió proceder con una concepción de las personas como in- 
dividuos que sólo razonan, relegando sus otras características y capacidades, incluso sus procesos de maduración como personas. "El deliberador moral abstracto no tiene capacidades que puedan ser mostradas sólo a través de su desarrollo", a diferencia de la más rica psicología moral mostrada en el Bildungsroman ${ }^{15}$ (Diamond, 1998: 52). Varios filósofos afirman estas ideas a un nivel general. Nussbaum es "una excepción distinguida" al proveer también lecturas literarias a profundidad, subraya Haines (1998: 30). Esto añade peso a su visión sobre si la literatura puede ser un sustituto para la ética filosófica. Concluye más bien que la poesía y la filosofía proporcionan maneras complementarias para el pensamiento ético y que un papel de la crítica literaria es el de mediar entre ambas (Haines, 1998: 32).

Los informes escritos provocan imágenes, pero tratan de informarnos y de conducir nuestra interpretación más de lo que lo hacen las pinturas. Construyendo un sentido de persona real por medio de detalles evocativos, repasando situaciones y eventos en los cuales podríamos imaginarnos a nosotros mismos, y derivando efectos inesperados, puede concitar nuestra simpatía hacia lo descrito. Las novelas normalmente nos presentan escenarios que se vinculan con nosotros para garantizar que comprendemos. Aspiran no sólo a mostrar un proceso en sus personajes, sino también a inducir su contraparte en el lector, y por ende, a ser más accesibles y profundas que los reportajes.

Wayne Booth argumentó en The Rhetoric of Fiction (1961) que la afinidad "es producida y controlada mediante los recursos técnicos de acceso, cercanía y distancia" (Nair, 2000: 114). Primero: "Somos más dados a simpatizar con personas cuando contamos con mucha información acerca de sus vidas íntimas, motivaciones, temores, etc." (2000: 110). Éste es el método evitado por la economía (y por las imágenes vistas desde lejos), cuyos análisis racionan de manera estricta tanto la información como la simpatía, siguiendo la premisa del famoso economista Denis Robertson de que nada es más escaso que

15 Novela de aprendizaje o de formación que muestra el desarrollo físico, moral, psicológico o social de un personaje, generalmente desde la infancia hasta la madurez. [Nota del traductor.]

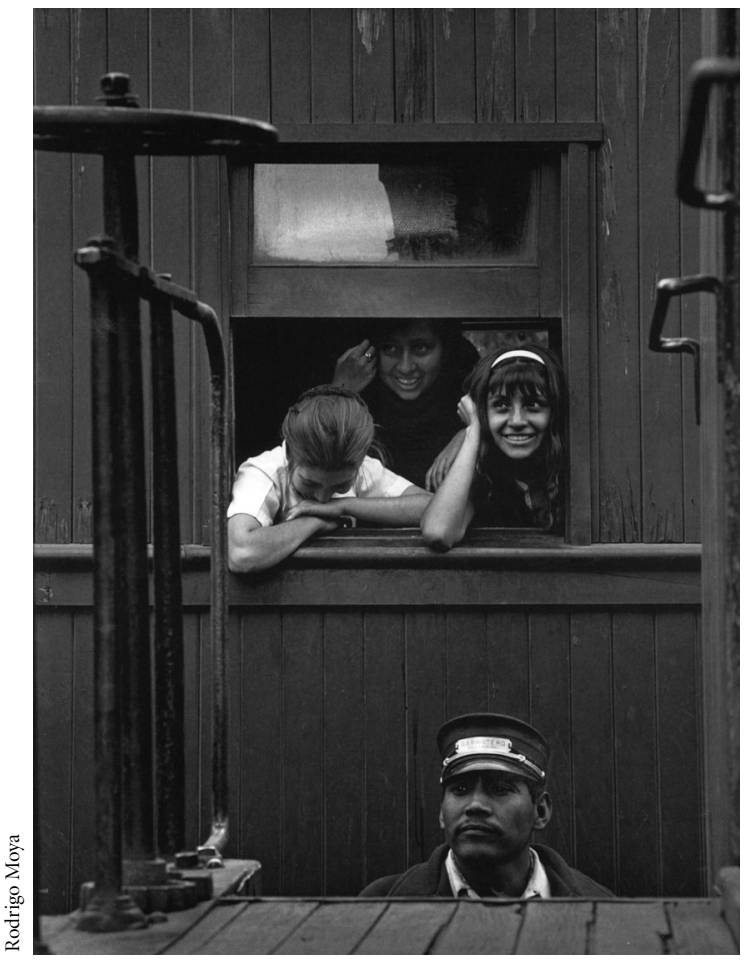

Ferrocarril viejo México-Cuautla, ca. 1964.

el amor por el prójimo. Segundo: "Simpatizamos con las personas cuando vemos que otras que no comparten nuestro acceso a sus vidas íntimas [Des Gasper: por ejemplo, los economistas externos], las juzgan de manera severa o incorrecta. En la vida obtenemos este tipo de información a través de la intimidad y la amistad. En la ficción la obtenemos [...] bien reportada de manera confiable por el narrador o a través del acceso directo a la mente de los personajes" (Nair, 2000: 110-111).

Nussbaum propone que "hay algunas visiones morales que sólo pueden ser expresadas adecuadamente a través de las novelas", gracias a su escala y estilo de investigación, informa Cora Diamond (1998: 39). La principal recompensa moral de las novelas resulta no solamente de seguir las experiencias de los personajes y cómo eligen, sino, dice Nussbaum, de atender la manera en que el novelista reflexiona sobre esto. La reflexión no se presenta como argumentos formales generales, aunque son éstos lo que la mayoría de los filósofos busca en la litera- 
tura, a menudo insensibles a sus ambigüedades, previenen Diamond, Nussbaum y otros. La literatura mantiene también la conciencia de que en la vida existe más de lo que sabemos o entendemos, mientras que buena parte de la ética es estrecha y confiadamente sabihonda (Diamond, 1998: 51). La literatura no nos ofrece sistemas propositivos, pero desarrolla nuestra sensibilidad e imaginación —nuestro corazón y alma (Adamson, 1998: 89). Las novelas pueden arrojar particular claridad sobre cómo "el yo deviene en ser como un proceso dialógico" (Hillis Miller, cit. por Parker, 1998: 13), más que ser inherente como la carne de una nuez. "La única manera de explicar quiénes somos es narrar nuestra propia historia" (Nair, 2000: 109). Se puede sostener, entonces, que no sólo las novelas sino también los testimonios reflexivos - como en $L a$ voz de los pobres, y especialmente en informes que hayan sido reducidos y procesados de maneras menos pesadas - pueden también desempeñar este papel.

\section{Simpatía y compromiso, compasión y piedad}

Otra enorme virtud del trabajo de Nussbaum es su atención a las emociones, incluyendo sus roles en el juicio ético y en la acción ética, y en sus riesgos, distorsiones y determinantes. Las emociones aparecen como una capability central en la lista de Nussbaum, y también forman parte de las capabilities de afiliación, juego y relaciones con otras especies. Para describir y explicar, y para persuadir y actuar de manera efectiva, necesitamos entender, emplear e influir en una gama de estados mentales mucho más allá de la 'utilidad' y la 'preferencia'. De igual manera, necesitamos más atención al dominio del cuidado, además de los de la libertad y la justicia (Van Stavaeren, 2001), y a los temas resaltados por Sen en la década de 1970 bajo las etiquetas 'simpatía' y 'compromiso', aunque desde entonces no los ha enriquecido mucho.

Nussbaum apunta que uno no puede articular plenamente la teoría del razonamiento más compleja, predictiva y normativa propia de Sen, sin incluir destacadamente las emociones, en las cuales parte de ese razonamiento está incorporado (2001a: 392): por ejemplo, ¿qué nos motiva para ver las cosas como otros las ven? Nussbaum explora aún más. La compasión (su término preferido para simpatía) desempeña un papel central en la vida moral y, por tanto, en la social: 'una suerte básica de compasión por quienes sufren, basada en significados aprendidos en la infancia' parece virtualmente universal y casi natural, y con frecuencia sobrevive incluso a los embates masivos de las fuerzas opuestas de la ideología y la socialización (2001a: 389). "En contraste, una teoría moral abstracta no habitada por esas conexiones de la imaginación y la simpatía puede fácilmente ser desviada a extremos malvados, porque su significado humano no es claro" (2001a: 389-390). La emoción no es, ciertamente, una guía suficiente, enfatiza Nussbaum, pero es un componente necesario, y las emociones pueden ser educadas.

Nussbaum distingue empatía, habilidad para imaginarse la experiencia de otra persona, de compasión, vista como preocupación ("una emoción dolorosa") 'por el inmerecido infortunio de otra persona' (2001a: 301). Revisa entonces el diagnóstico de Aristóteles de la estructura intelectual de la compasión. Aristóteles lo describió como una preocupación por el infortunio de otra persona, que surge cuando ese infortunio es visto por el observador como: 1) importante, 2) inmerecido, y 3) de un tipo que pudiera ocurrirle a él mismo. Nussbaum respalda las primeras dos visiones postuladas y da buenas razones para considerar la tercera como factor contribuyente relevante, pero no un rasgo necesario. Lo remplaza con 3') el infortunio sucede a alguien (o algún ser) que está presente dentro del universo de interés del observador. La re-especificación parecería significarse como una descripción empírica. El diagnóstico ayuda a Nussbaum a encontrar impedimentos a la compasión: envidia, vergüenza y disgusto, los cuales desestiman el sufrimiento de otros o lo excluye del universo de interés propio (2001a: 423); y temor a adquirir obligaciones de ayudar (2001b: xxxvii). El diagnóstico también implica maneras para tratar de promover una compasión adecuada, mediante la difusión de teorías más apropiadas de: 1) importancia ética, 2) causación y merecimiento, y 3) el alcance de la comunidad ética: tareas todas centrales para la justicia global.

Podemos investigar también el segundo componente de Aristóteles: la idea de que la compasión no aplica al 
infortunio merecido. El término "compasión" — sentir con o por el sufrimiento de otro, "lástima que inclina a uno para ayudar o ser piadoso" (Diccionario Oxford) no implica que por etimología o convención el sufrimiento sea inmerecido (véase también Comte-Sponville, 2002: 106 ss.), aunque puede ciertamente ser un factor que lo refuerce, como por ejemplo, en el caso de muchos niños en países muy pobres. Nussbaum cita un estudio que sugiere que los estadounidenses contemporáneos normalmente dividen los casos claramente en aquellos en los que las acciones propias de una persona pueden hacer una diferencia y en los que esa persona es entonces considerada responsable de lo que ocurra, y otros casos en los que lo que sucede es considerado simplemente fuera del control de la persona (Nussbaum, 2001a: 313). Así, si uno proclama que las víctimas de SIDA en África están sufriendo debido a errores de ellos mismos y de nadie más, y no necesitan ser ayudados, esto no es percibido como falta de compasión; y si uno declara que los granjeros de países del norte podrían sufrir quebrantos de sus planes de vida debido al deterioro en su estándar de vida acostumbrado, entonces los subsidios a los granjeros y las barreras al comercio cobran la apariencia de compasión. Los estoicos advirtieron contra este carácter manipulable y parcial de la compasión (Nussbaum, 2001a: cap. 7). Nos preocupa en estos días un 'matrimonio' entre los marcos de referencia de Aristóteles y las percepciones estadounidenses contemporáneas. Podríamos al menos dejar de insistir en que la gente sólo puede ser considerada como totalmente responsable o como no responsable en absoluto.

\section{Estrategia retórica: "crítica interna"}

La fuerza retórica de Nussbaum incluye lucidez, una amplia gama de ejemplos y una sinceridad evidente. Una fortaleza adicional es su práctica ocasional de un estilo de "crítica interna", expuesto en un ensayo de la década de 1980 escrito conjuntamente con Sen. Ellos arguyeron que la gama de fuentes intelectuales y recursos disponibles en una cultura le proporcionan bases para que ésta aprenda y evolucione, inclusive en respuesta a influencias del exterior, más que a través de pedir aceptación de paquetes de ideas 'arrojados en paracaídas' que pueden carecer de resonancia local, relevancia o aceptación. Es más probable que los comentaristas y críticos tengan influencia si construyen en gran medida a partir de dichas fuentes y recursos internos. El proyecto global ético de Hans Küng ofrece un buen modelo de cómo construir tanto desde adentro como desde afuera.

Thanh-Dam Truong aconseja que un proyecto para la justicia global debe obtener aceptación general por medio de diálogos interparadigmáticos y transformación mutua y, por consiguiente, debe evitarse una manera vertical de persuasión que puede potencialmente eliminar la diversidad cultural (Truong, 2006). De ahí que Jan Nederveen Pieterse (2006) llame entonces a poner atención en las tradiciones del cosmopolitismo aparte de las de las élites occidentales y que Ananta Giri (2006) pida múltiples transformaciones en los discursos cosmopolitas occidentales para hacerlos menos provinciano-occidentales y más conscientes de los requerimientos del autodesarrollo.

Mientras que los trabajos de Nussbaum de finales de la década de 1980 y de principios de la de 1990 sobre capabilities dependían mucho de una visión neoaristotélica externamente especificada de "la buena vida para el hombre", su trabajo desde la mitad de la década de 1990 ha seguido el proyecto de "crítica interna" y busca acuerdos en las conclusiones, aun donde haya desacuerdo sobre las premisas y rutas. En el largo capítulo sobre religión de Women and Human Development (2000a), por ejemplo, Nussbaum escucha con toda atención al interior de las culturas. Comenta sobre el proceso de construir dentro de una tradición moral utilizando sus propias categorías y supuestos. Las tradiciones son entendidas como algo más que un conjunto de prácticas fosilizadas y con la conciencia de que contienen subtradiciones de reflexión y el potencial para evolucionar. Al mismo tiempo, advierte el peligro de que el discurso interno de la ética basada en las tradiciones pueda convertirse en un respaldo etnocéntrico, y la necesidad también de insumos externos críticos.

En este difícil acto de equilibrio, algunos aspectos de las tácticas y el tono de Nussbaum pueden ser cuestiona- 


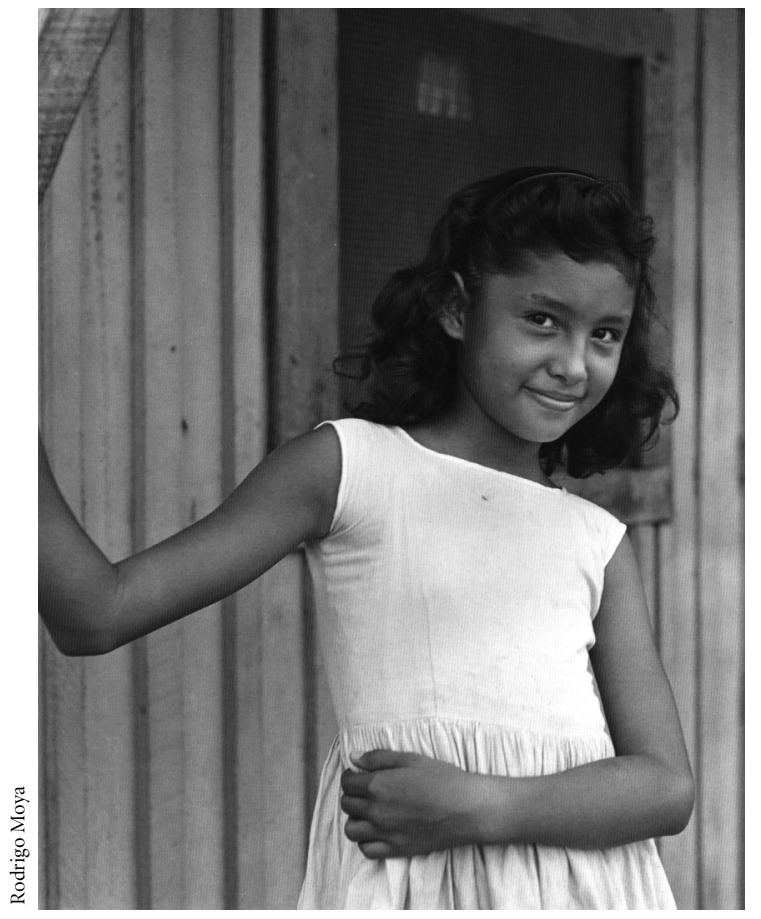

Puerto Armuelles, Panamá, 1965.

dos. De manera contraria a las expectativas de sus críticos, algunas veces puede llevar la conciliación con las prácticas locales vigentes demasiado lejos. Nussbaum parece excusar lo inexcusable en la India: "la nación no está en este momento en condiciones de hacer cumplir ya sea esas leyes [que establecen la educación obligatoria] o las leyes contra el trabajo infantil" (2000a: 231), una declaración que carece de credibilidad dados los logros de Sri Lanka y Kerala al respecto. De igual forma, adopta una línea política táctica para aceptar el estatus obligatorio de la ley islámica personal para los musulmanes en India. Puede caer en la trampa de promover guetos cuando concluye que retirar la presión del Estado para la aplicación obligatoria de la ley musulmana de familia podría bajo las actuales circunstancias ser "difícil de disociar [de] [...] una relegación de los ciudadanos musulmanes a un estatus de segunda clase" (2000a: 178); y de la misma manera en su proclama que "dada la historia de los musulmanes en India, parecería que cualquier abolición del sistema de ley islámica se convertiría en una seria amenaza a la libertad religiosa" (2000a: 211). La mitad de los ciudadanos musulmanes, las mujeres, ya tienen un estatus en verdad de segunda clase, establecido por dicha ley, y la propuesta no es abolir la ley personal islámica, sino dar a las personas la opción de acogerse a la ley civil, un derecho que debería ser aplicable para todos los ciudadanos. Prevenir este derecho es la amenaza real a la libertad religiosa, ya que transfiere toda la libertad religiosa de los musulmanes a los mullahs, quienes determinan el significado y la evolución de los dogmas religiosos musulmanes. Una ley indefendible, protegida políticamente por razones electorales, parece más probable que ayude a que otros sientan que los musulmanes son ciudadanos de segunda clase. Desafortunadamente, el conservadurismo defensivo y la denigración externa pueden verse mutuamente fortalecidos.

\section{Presunciones cosmopolitas: psicológicas, filosóficas y sociológicas}

Nussbaum diseña un elocuente e intrincado llamamiento a la conciencia e interés cosmopolitas. ¿Cuáles son sus presunciones, y cuáles las presunciones requeridas para el cosmopolitismo ético? "Presumir", dice el diccionario, es tomar algo por cierto, asumir, confiar o depender. Y "presunción" significa creencia o supuesto basado en evidencia razonable, una razón o bases sobre las cuales presumir. Los aspectos clave aquí involucrados incluyen:

- Los actores que están en discusión y/o los destinatarios: ¿quiénes son y cuál es su ambiente geográfico, organizacional e intelectual?

- Los supuestos sociológicos subyacentes en la discusión ética —sea cosmopolita, contractualista o comunitarista-; en otras palabras, los supuestos acerca de la(s) naturaleza(s) actual(es) y emergente(s) del concepto de persona, identidad, residencia y medios de sustento.

- El temor de que el cosmopolitismo represente una agenda de dominación metropolitana frente a la visión contraria de que las posturas del relativismo ofrecen menos protección contra las intervenciones metropolitanas y no dan bases desde las cuales criticarlas. 
- La conexión entre debates académicos e instituciones y movimientos reales más allá de la academia: ¿cuáles son los supuestos o hipótesis acerca de las retóricas efectivas para influir y persuadir, y para qué públicos?

- La cuestión de los supuestos políticos y organizacionales sobre los marcos y mecanismos institucionales, el poder y las estrategias efectivas para el cambio.

\section{Los presuntos cosmopolitas potenciales}

La obra de Nussbaum busca desarrollar "una concepción del propósito de la cooperación social focalizada en el compañerismo y el interés personal" (Nussbaum, 2004: 4), "[pues] entre los rasgos característicos del ser humano está un imperioso deseo por el compañerismo, es decir, por la vida en común, no de cualquier clase, sino una vida pacífica y organizada de acuerdo con la medida de su inteligencia, con aquellos que son de su clase" (Grotius, On The Law of War and Peace, cit. por Nussbaum, 2006: 36).

Nussbaum señala que las personas no son regateadores (bargainers) asociales, sino criaturas sociales morales. Pero la sociabilidad es parte de una sociedad, de un grupo - "con aquellos que son de su clase", como observó Grotius. ¿Qué tanto se extiende y puede extenderse esto globalmente? ¿El compañerismo es cósmico en escala? Alineadas contra Nussbaum, en palabras de David Harvey, "están todas las versiones de cosmopolitismo con adjetivos, diversamente descritas como arraigado, situado, vernáculo [etc., etc.] [...] en la creencia que la lealtad desinteresada a la categoría abstracta de 'lo humano' es incapaz en teoría, mucho menos en la práctica, de proporcionar algún tipo de arrastre político" (Harvey, 2000: 530).

Las relaciones humanas forman una serie de círculos concéntricos (como enfatiza Nussbaum siguiendo a los estoicos) y nuestras emociones están inevitablemente condicionadas por ese hecho. La capacidad de empatía es más fuerte con personas que ya están cerca de nosotros. Ésta puede aun ser muy intensa con personas con las que ahora ya compartimos algo, aunque no las conozcamos personalmente. Y tiende a volverse más abstracta mientras más se aleja uno de la esfera del "mí y mío". ¿Cómo aceptar entonces tanto la radicación de la emoción en situaciones locales como el sentimiento de responsabilidad global? Ésta de ninguna manera es una cuestión retórica."Pienso que el desafío es crear 'concentricidad' de una manera que realmente se extienda hacia fuera — dice Nussbaum—, más que dibujar la línea en alguna parte de manera que uno demonice lo que está afuera de ella" (McLemee, 2001).

La concepción de círculos concéntricos de los estoicos ya contiene, visualmente, el potencial para un cosmopolitismo enraizado. ¿Cómo construirlo? Más que confiar únicamente en un lazo emocional de carácter universal, como el énfasis en la membresía de la familia humana, podemos también construir, de la misma manera que construimos otras cosas, conectando una cosa con la otra y la otra, conectando personas y sus intereses con y a través de sistemas de instituciones. Esta construcción es un proceso a muy largo plazo, pero históricamente en marcha sin duda, y vinculado con las crecientes interconexiones a lo largo de nuestro cosmos.

\section{Presunciones acerca del cosmos: un mundo de interconexión}

El comunitarismo - postura para la cual la ética está, debería y tiene que estar enraizada en comunidades fuertes (sean locales, tribales o, menos plausiblemente, nacionales) — ha sido criticado amplia y enérgicamente por descansar en una débil y anacrónica sociología ${ }^{16}$. De la misma manera, debemos realizar un escrutinio sociológico concienzudo respecto al cosmopolitismo. Onora O' Neill argumenta con fuerza $(1996,2000)$ que las presunciones que nosotros hacemos en nuestros negocios diarios acerca de otras personas alrededor del mundo con quienes interactuamos —en el sentido de que son criaturas separadas con claros pero limitados poderes - tienen una implicación ética. Resalta tres aspectos: 1) "plurali-

16 Véase, por ejemplo, Rustin (1995) y otros ensayos en Miller y Walzer (1995). 
dad": "que hay otros (vistos como separados del agente)"; 2) "conexión": "que esos otros están, no obstante, conectados con el agente (sea que él o ambos puedan actuar sobre el otro)"; y 3 ) "finitud" o, dicho alternativamente, agencia y vulnerabilidad: "que esos otros tienen poderes limitados pero determinados" (O’Neill, 1996: 101). Nuestras acciones pueden implicar esas presunciones, que "otros son agentes y sujetos" (ibid.), aun si conscientemente lo negamos. No podemos hacer esas presunciones durante nuestras interacciones y transacciones pragmáticas y prudenciales y luego borrar las presunciones durante la discusión de nuestras interconexiones éticas, nuestros mutuos deberes y derechos: "lo que es asumido con propósitos de actividad [por ejemplo, comercio] debe también ser asumido al fijar el alcance de la consideración ética" (1996: 106; adiciones mías).

El argumento de O'Neill descansa en, y su alcance varía de acuerdo con, los hechos de interacción y transacción globales. De manera correspondiente, diferentes realidades e interpretaciones de la interacción global pueden dar lugar a distintas posturas sobre cosmopolitismo. Diferentes concepciones sociológicas de patrones actuales y emergentes de la interacción global sustentan distintas concepciones de la ética global. Michael Walzer (1994) contrasta los discursos éticos "robustos" en las esferas doméstica y nacional con el discurso ético "ligero" que cruza lo nacional. Los críticos han señalado que su imagen de mundos vitales (lifeworlds) ${ }^{17}$ es incompleta y que una dicotomía doméstica-internacional es desorientadora. En ella se subestiman tanto los lenguajes universalistas que el debate moral y político moderno emplea como estándar "producto de sociedades que se han vuelto racionalizadas y diferenciadas" (Rustin, 1995: 38) como las realidades de la amplia interconexión global. A partir de una detallada consideración de la diversa interconexión de esta época, David Held (2004) y otros no ven un sistema construido por bloques de naciones - ni siquiera Estados Unidos - sino un mundo de innumerables comu-

${ }^{17}$ Las maneras modeladas en las cuales un ambiente físico es funcionalmente significativo dentro de una cierta actividad. [Nota del traductor.] nidades que se traslapan unas a otras. Como en el "cosmopolitismo hincado" de Toni Erskine (2000), una ética inclusiva puede entonces emerger, pues los individuos son simultáneamente miembros de muchas comunidades no territoriales, traslapadas y moralmente constitutivas (Gasper, 2005). Necesitamos imágenes de círculos traslapados, no sólo de círculos concéntricos.

Truong (2006) expresa la preocupación de que el proyecto de Nussbaum de extender el "liberalismo político" a una escala global pudiera ser un ejercicio más tendencioso y tenso de lo que Nussbaum imagina. Ella pone en duda cualquier llamamiento a una supuesta intuición universalizable, incluso si fuese visto como un llamamiento a largo plazo a una intuición eventual bien informada y bien reflexionada bajo circunstancias no coercitivas. Truong evoca el contraste entre una noción de un universo ético y la de un "multiverso" ético. Éste último descansa en una ontología social diferenciada que toma en cuenta al humano socialmente encajado y al universo que él o ella produce. En esta última visión, cada universo ético-social tiene su propia y distintiva lógica interna pero se puede relacionar con otros de manera constructiva. Cada uno es adjunto del otro y ambos sirven para interrogarse mutuamente sobre sus conductas.

\section{Retóricas cosmopolitas en relación con públicos y contextos}

Algunas preocupaciones recurrentes surgen cuando Nussbaum trata de conducir a sus colegas filósofos, a economistas y otros asociados hacia concepciones más completas de la personalidad humana y sus obligaciones. Primero, para sostener una conversación con filósofos analíticos, su estilo permanece relativamente abstracto - no abstracto si se compara con los filósofos, sino más bien en comparación con la mayoría de los escritos de las ciencias sociales y las humanidades. Para tener credibilidad en estos últimos campos, sin embargo, en un tópico como el cosmopolitismo, uno debe mostrar fundamentos copiosos en diversas, intrincadas y rebuscadas realidades. Frontiers of Justice representa, en contraste, una conversación con Rawls en su terreno de la ética filo- 
sófica. Segundo, dado este lenguaje abstracto y generalizador con el cual una "verdad que aspira a serlo le habla al poder", los críticos aparentemente temen que una verdad tan estrecha tenga tanto acceso directo a un poder demasiado estrecho y grandioso - a pesar o aun debido a la afiliación de Nussbaum a las agendas de derechos humanos y desarrollo humano de las Naciones Unidas y no, de manera distintiva, a las agendas del Estado estadounidense.

\section{¿Cuáles abstracciones y cuándo?}

Nussbaum insiste en la primera oración de Frontiers of Justice que "las teorías de la justicia social deben ser abstractas", relevantes y justificables para una gama de situaciones. "Por otro lado, las teorías de la justicia social también deben dar respuesta al mundo y sus problemas más urgentes" (Nussbaum, 2006: 1), cosa que el libro intenta de forma manifiesta. Sin embargo, para los lectores de ciencias sociales, los capítulos sobre justicia internacional contienen más bien poco acerca de las realidades de las relaciones internacionales en el mundo moderno. Ese conocimiento permanece tácito o al margen, sólo usado como motivación inicial y muy brevemente en la sección final del capítulo 5 sobre "Diez principios para la estructura global".

Onora O'Neill aborda el tema de la abstracción y el realismo en una teoría de la justicia de la manera siguiente $(1996,2000)$ : debemos abstraer diferencias irrelevantes (tales como, en ocasiones, el género), aunque la irrelevancia de tales diferencias puede depender de la situación. Y debemos incluir diferencias relevantes (tales como, en ocasiones, el género), cuya relevancia, de nuevo, dependerá de la situación. Así, debemos buscar la abstracción sin idealización y la sensibilidad al contexto sin caer en un relativismo puro que sólo ratifique lo que sea que exista (Gasper, 1996b). Nuestro panorama de cuándo una diferencia es relevante se construye por medio del examen y el debate de casos a la luz de principios y del debate de principios a la luz de casos. Esta dialéctica es observable a lo largo de la obra de Nussbaum, incluyendo Frontiers of Justice, pero más en los capítulos sobre la in- capacidad que en aquellos que tratan sobre relaciones internacionales.

McCloskey (2006) sugiere que Nussbaum abstrae demasiado y no sigue su propia intuición de que una perspectiva de un rango de las virtudes humanas centrales no puede ser producida por un discurso que ve a las personas más estrechamente; aquí la parsimonia es un error. Nussbaum ha escrito de manera extensa sobre dichas virtudes, pero en Frontiers of Justice busca mantener una conversación con los contractualistas. La lección consiste en ser más explícito en las abstracciones que uno está haciendo, cuándo y por qué.

\section{¿Nosotros somos el mundo?}

Nussbaum recurrentemente provoca la reacción que su visión cosmopolita es un intento de mandar a otros. ¿Quién es el "nosotros" en el siguiente pasaje?: "Nosotros no podemos llegar a esta conclusión [que un acceso igualitario a una educación primaria y secundaria es un derecho humano fundamental] haciendo encuestas y preguntándoles a las personas qué es lo que prefieren actualmente pues las preferencias existentes respecto de asuntos de educación (especialmente, tal vez, las preferencias de las mujeres) frecuentemente están deformadas" (Nussbaum, 2006: 279). Esto puede ser leído ya no como el "nosotros" del autor sino como el referido a un grupo de pares de gobernantes ya educados.

De hecho, existe una paradoja inevitable en la insistencia del liberalismo en el sentido de que las personas deben tener la oportunidad de salirse de cualquier esquema cultural dado, excepto del liberal. La no liberabilidad involucrada ciertamente parece menor, sin embargo, que aquella que aparece bajo esquemas culturales y de políticas que implantan opciones únicas y no permiten que nadie se salga, aún y cuando él o ella desee hacerlo, para entrar a un sistema que proporciona opciones. El principio liberal permite a las personas adoptar su propio estilo de vida pero no les permite impedir que otros hagan lo mismo.

Presentar un punto de vista es aconsejar, no mandar; la impetuosa reacción sugiere un temor de que parte de la 
audiencia acepte el punto de vista. Si ninguna verdad en potencia puede ser expresada, la reacción habrá bloqueado el enfoque dialógico por el que supuestamente aboga y puede implícitamente convertirse en una defensa del poder de las elites existentes. Sin embargo, este temor está parcialmente fundado en las historias del imperialismo. Brennan en ocasiones presenta al cosmopolitismo como esta única variedad: "es un discurso de lo universal que es inherentemente local —un localismo que siempre es subrepticiamente imperial. Normalmente el cosmopolitismo construye utopías políticas so capa de estética o ética, de tal manera que puedan desempeñar, de manera más efectiva, lo que frecuentemente da la prueba de ser, bajo inspección, un papel económico" (Brennan, 2001: 81). Harvey observa un panorama más rico de variedades de cosmopolitismo que el visto por Brennan pues, comparativamente, "ve el capitalismo como un proceso mucho más desigual, matizado, amíbico y anárquico" (Gidwani, 2006: 16).

¿Quién es el público potencial? La teoría de Nussbaum se puede usar de varios modos. Como estadounidense puede influir en organismos en Estados Unidos a propósito de lo que éstos apoyan o no internacionalmente. Como figura internacional puede tal vez influir en cuerpos internacionales, tales como el Programa de Naciones Unidas para el Desarrollo, respecto a lo que promueven o no. Como intelectual, puede influir en personas alrededor del mundo, quienes a su vez pueden influir en los organismos oficiales. En cada caso puede sostenerse que la responsabilidad primaria por el uso de sus ideas descansa en cualesquier cuerpo que las adopte.

La estrategia discursiva de Nussbaum aún genera temores de dominación del norte, o al menos de la dominación ejercida por el tipo equivocado de personas del norte (ignorantes, demasiado poderosas, obstinadas), y de un acceso privilegiado para las élites metropolitanas amantes de la violencia - $\mathrm{o}$ al menos del mal uso de ideas abstractas bien intencionadas. ¿¿Cómo afectará a esta percepción su más clara afiliación de ahora con los derechos humanos? Los Derechos Humanos Internacionales (DHI) no fueron teorizados explícitamente en el momento de su adopción en la década de 1940, fuera de decir que eran compatibles con muchas tradiciones. El lugar central de su exposición fue Estados Unidos, como parte del anticomunismo y del posnazismo. ¿Por qué debiera ahora teorizarse más acerca de los derechos humanos? Una diferencia significativa con la década de 1940 es que desde entonces poderosas fuerzas en la cultura política de Estados Unidos han fallado en aceptar y adoptar el régimen de los DHI; poseen su propia versión, visión y proyecto. Esta corriente en Estados Unidos rechaza la idea de obligaciones internacionales (excepto el cumplimiento de contratos), aunque periódicamente considera saber lo que es mejor para todos y puede determinar implantarlo por la fuerza. Un público central implícito en el trabajo de Nussbaum es no sólo filósofos académicos, sino también un público estadounidense más amplio, como puede observarse a partir del estilo y alcance que ha escogido ${ }^{18}$. Su insistentemente sofisticado mensaje al público estadounidense sobre temas de cosmopolitismo, derechos humanos y desarrollo humano es una gran contribución. Esto hace que algunos críticos se preocupen más.

\section{Estados Unidos y otras audiencias}

La audiencia primaria implícita en Women and Human Development fue estadounidense, como puede verse en sus extensas discusiones de casos legales de Estados Unidos y en el estilo de su periódico consejo a las feministas de Occidente. De manera similar, se puede argumentar que el conjunto más importante de audiencias para el discurso cosmopolita de Frontiers of Justice radica en Estados Unidos, dado tanto por su poder como su insularidad. Nussbaum se ha enfocado primariamente a esta audiencia de muchas maneras —en sus ejemplos, sus objetivos de debate y el "nosotros" al cual en ocasiones

\footnotetext{
${ }^{18}$ Así, algunas veces el "nosotros" de Nussbaum significa Estados Unidos. Un ejemplo (en una sección sobre ayuda estadounidense) es: "En la medida que una nación fracasa en apoyar tales metas [como el poder e igualdad para las mujeres] pública y constitucionalmente, haríamos lo correcto al proceder de una manera más cautelosa, pero deberíamos probablemente todavía estar en nuestro derecho de enfocar la ayuda a proyectos que nos parecen moralmente buenos" (Nussbaum, 2006: 261).
} 
se refiere- Surge una pregunta: ¿qué formas de enfoque y estrategia retórica tienen la posibilidad de alcanzar un mayor efecto en esta audiencia? Por un lado, el trabajo de Nussbaum sobre la justicia global, el cuidado y las emociones pretende contribuir a cambios a largo plazo por medio de la influencia en sistemas legales, la currícula educativa y la formación profesional. El trabajo de Nussbaum no debe ser evaluado como un arma en debates políticos de corto plazo en Washington, D.C., en los que puede esperarse que no tenga influencia. ¿Pero para el trayecto largo cuáles métodos pueden ser efectivos? Los que detentan el poder en Estados Unidos enfatizan los lenguajes de libertad, elección y autosatisfacción (y de "hogar" y "seguridad"). En Development as Freedom, Sen (2000) adoptó un lenguaje que puede resultar atractivo para la audiencia estadounidense de la tendencia principal, así como a diversos grupos en otras partes. Haq, en los Informes sobre Desarrollo Humano del PNUD encontró una retórica "humana" que es igualmente global pero menos estadounidense y Nussbaum parece estar más cerca de ésta.

Una segunda pregunta: ¿qué tipo de discursos son relevantes en otros contextos? En contextos de políticas nacionales e internacionales las perspectivas cosmopolitas son relevantes en debates sobre comercio, ayuda, apoyo, migración, multiculturalismo, gobernanza global, el sistema de las Naciones Unidas y similares. Están presentes en debates académicos contra el "realismo" en las relaciones internacionales, cuando se presenta como una postura ética, y en disputas legales tales como el alcance de las leyes sobre derechos humanos. Pero cada contexto posee sus propios requerimientos de profundidad y antecedentes hacia los cuales Frontiers of Justice no está orientado. En una conferencia reciente sobre la Carta de la Tierra (Earth Charter, Amsterdam, 2005) se repitió el siguiente tipo de consejo: "únicamente si este lenguaje se conecta al de la religión y/o cultura local puedo hacer algo con él en mi país". El Global Covenant de David Held (2004), en contraste con Frontiers of Justice, se sumerge en una guía muy completa para las agendas, términos y productos burocráticos internos recientes de gobernanza global y brinda un programa práctico mucho más elaborado. Frontiers of Justice aparece sintonizado, más bien,

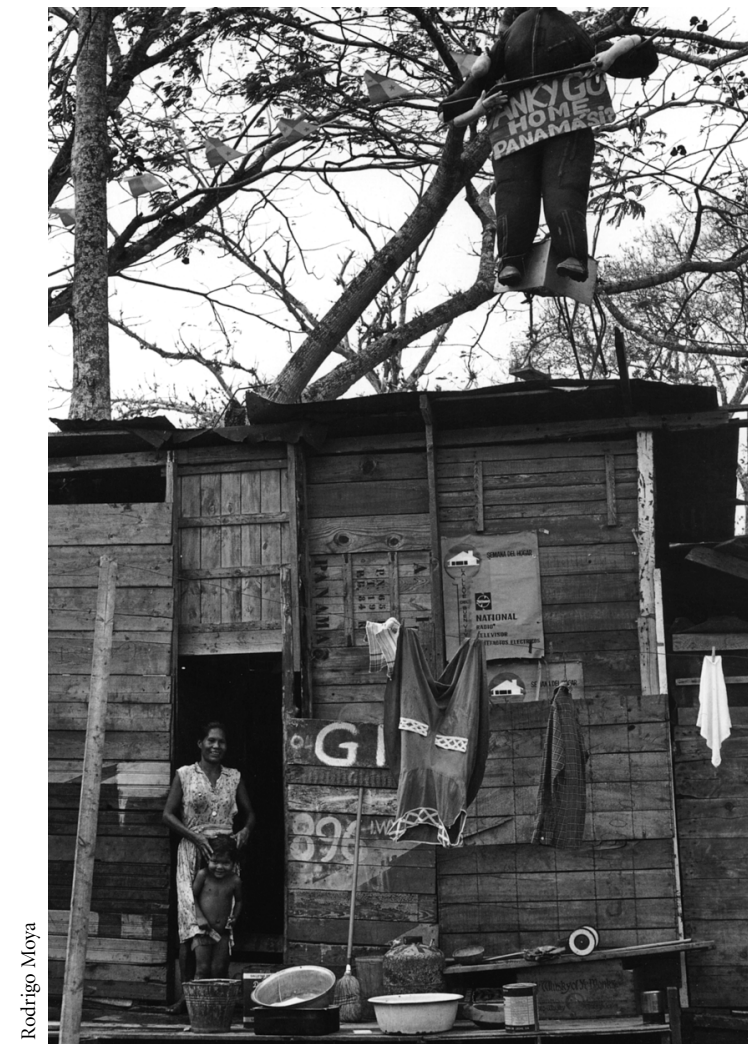

Panamá, Panamá, 1965.

y de manera comprensible, a dos audiencias principales: los filósofos y un público en general de los países del norte (pero especialmente esdtadounidense) de estudiantes e intelectuales potencialmente simpatizantes, la audiencia cuya educación liberal Nussbaum discutió en Cultivating Humanity.

\section{LA POLÍTICA DEL CAMBIO}

\section{¿Metas prácticas y útiles, institucionales y de política?}

Nussbaum, como la mayor parte de los cosmopolitas contemporáneos, no aboga por un Estado mundial pues es "muy poco probable que tuviera un nivel decente de rendición de cuentas para sus ciudadanos" y si "se tornara injusto no habría un recurso correspondiente" de 
ayuda externa (Nussbaum, 2006: 313). La soberanía local tiene también un valor moral: significa que el pueblo se dé leyes a sí mismo. Por tanto, "la estructura institucional a nivel global debe permanecer delgada y descentralizada" (2006: 314). Después sugiere un conjunto de diez principios para esta estructura global (2006: 315-23):

1. "Sobredeterminación de responsabilidad: lo doméstico nunca escapa de ella” (2006: 315).

2. "Soberanía nacional, excepto en un limitado rango de circunstancias" (2006: 316).

3. Un deber de las naciones ricas de dar mucho (más).

4. Obligación de las corporaciones multinacionales de invertir socialmente y promover las capabilities humanas donde trabajen, y promover "buenas condiciones laborales" (2006: 318).

5. Un sistema económico global justo, no el actual.

6. "Una esfera pública global delgada, descentralizada, y sin embargo fuerte" (2006.: 318), incluyendo, por ejemplo, algunas formas limitadas de impuestos globales, una corte criminal mundial, regulaciones ambienta- les mundiales, estándares de trabajo globales.

7. Presión internacional a favor de los que sufren desventajas dentro de las jurisdicciones nacionales.

8. Cuidado de los débiles, "los enfermos, los ancianos, los niños y los discapacitados", como una preocupación global y sin dejar toda la carga en los miembros femeninos de las familias.

9. La familia como preciada, pero no sacrosanta (por ejemplo, no libre para descuidar a las niñas).

10. Todas las partes deben apoyar la educación, "como una clave para empoderar a quienes actualmente se encuentran en desventaja”.

"La asignación [de deberes aquí] es una asignación ética $[\ldots]$ : no existe una estructura coercitiva sobre el todo que pueda obligar a ninguna parte a un conjunto definido de tareas" (2006: 315).

Tal vez de manera imprudente Nussbaum relaciona el tercer principio con "la cifra de 2\% del PIB [...] [como] un buen signo de lo que pudiera empezar a ser moralmente adecuado" (2006: 317), en lugar de concentrarse en el punto cinco, un sistema económico global justo, y en el tema de qué nivel de apoyo se requeriría para alcanzar capabilities básicas, el cual muy probablemente se encuentre muy por debajo de $2 \%$ si se combina con un sistema económico global justo. Murphy nota que la cifra de $2 \%$ proviene del consejo de Arthur Lewis y el economista de Chicago T. W. Schultz después de la Segunda Guerra Mundial, emitido durante un periodo en el que se realizaron algunas transferencias aún más grandes de $2 \%$ por el entonces mucho menos opulento Estados Unidos, a través del Plan Marshall, a receptores europeos, que eran mucho más ricos que los actuales países menos desarrollados.

Un sistema económico global justo pudiera ser el tema central. Nederveen Pieterse enfatiza que una globalización emancipatoria equivale a la re-regulación y a contrarrestar la globalización guiada por las corporaciones. Zoya Hasan se pregunta entonces si el quinto y sexto principios son compatibles:

Nussbaum propone una estructura institucional delgada y descentralizada a nivel global. Se conforma con las estructuras domésticas de naciones ricas, que tienen responsabilidades para redistribuir algo de su riqueza a otras naciones, y multinacionales, organismos internacionales y ONGs [que] adquieren alguna responsabilidad de promover capabilities. En justicia, deben soportar una carga proporcional. Sin embargo, la globalización corporativa es fundamentalmente una tendencia centralizadora que arrastra economías y sectores dispares a un mundo controlado por unos cuantos que toman las decisiones. Éstos son el Fondo Monetario Internacional, el Banco Mundial, la Organización Mundial de Comercio, que actúan en nombre de bancos y tenedores de bonos, y de países ricos y élites ricas de manera más general, y no en nombre de los trabajadores, campesinos y otras personas y naciones pobres. Uno se pregunta si hay espacio para una gobernanza descentralizada en este sistema en ausencia de una reestructuración radical. La justicia global necesita de manera muy urgente un sistema multilateral adecuado capaz de rendir cuentas internacionalmente, pues lo que estas instituciones y compañías multinacionales están socavando es la democracia ${ }^{19}$.

${ }^{19}$ Zoya Hasan, de la Jawaharlal Nehru University (Nueva Delhi), en
una presentación de las Conferencias Tanner, 2002, de Nussbaum. 
Murphy (2006) comparte esta preocupación, pero añade que en la sutil tarea de encontrar un camino hacia adelante políticamente viable, el idealismo callado pero profundamente arraigado de Nussbaum puede ayudar a establecer un camino medio que bien vale la pena.

Los diez principios aparecen como una especie de epílogo, sin mucho énfasis de Nussbaum, quien de manera justa juzga que éste es el punto donde el filósofo debe entregar la estafeta al practicante y al científico social. Consideremos las perspectivas generales asociadas a cómo puede ocurrir el cambio social.

\section{¿Cambiar estrategias?}

¿Cuáles supuestos, explícitos e implícitos, se hacen en las discusiones acerca de posibles rutas hacia el cambio cosmopolita? Una hipótesis puede ser: educación $\rightarrow$ cambio de valores $\rightarrow$ presión $\rightarrow$ acción; o, más específicamente, que los filósofos siembren las semillas y la sociedad civil las disemine y cultive, y aplique presión en los que toman las decisiones. El escenario de The Great Transition de un cambio mundial hacia la sustentabilidad, por ejemplo, prevé un eventual cambio de valores dirigido por la sociedad civil, y específicamente por los jóvenes (Raskin et al., 2002). ¿Cuán convincentes son los supuestos elaborados y qué consistencia existe entre la orientación actual del trabajo sobre el cosmopolitismo y las ideas acerca de las rutas de cambio?

Nussbaum es clara y enfática a propósito de la significación general de las ideas-valores: "Quizás nada hay más urgente - en un mundo crecientemente conducido por las corporaciones multinacionales y las ambiciones de poder que están incorporadas en el ámbito de sus operaciones- que articular un conjunto de metas humanamente ricas para el desarrollo y un conjunto de actitudes más generales acerca de los propósitos de la cooperación" (Nussbaum, 2006: 306). Algunos comentaristas dudan de si va suficientemente lejos respecto al alcance, contenido y posibles bases espirituales para el cambio de valores requerido, incluyendo la comprensión de las fuentes de compasión y compañerismo (Giri, 2006; Truong, 2006). También reflexionan sobre las bases sociales para el cosmopolitismo. El cosmopolitismo desde arriba está vacío sin el cosmopolitismo desde abajo, sin la experiencia real de ciudadanía o compañerismo mundial, advierte Nederveen Pieterse. David Harvey lo considera peligroso más que vacío:

\begin{abstract}
Si el cosmopolitismo de Nussbaum ha de llegar a ser cualquier cosa distinta de una esperanza piadosa, nada menor a una síntesis moderna (Alexander) humboldtiana, bastará [...]. El cosmopolitismo, en breve, está vacío sin su cosmos [...] [y] sin un entendimiento geográfico más unificado y crítico del mundo para servir de paralelo a la lucha por una ética cosmopolita [y contrarrestar la trivialización y demonización de regiones que los poderes metropolitanos desean controlar] [...]. El cosmopolitismo despojado de su especificidad geográfica queda como una razón abstracta y alienada, propenso, cuando baja a la tierra, a producir toda clase de consecuencias inesperadas y algunas veces explosivamente maléficas $[\ldots]$ no puede haber universalidad sin particularidad y viceversa (Harvey, 2000: 554-555, 557, $560)$.
\end{abstract}

En el espíritu de Cultivating Humanity de Nussbaum, sobre el cual hacía comentarios, Harvey subraya: "Pretender, entonces, que tenemos que hacer una elección entre cosmopolitismo 'universal' y 'enraizado' [...] es una falsa descripción” (2000: 559). "El punto geográfico no es para rechazar el cosmopolitismo, sino para fundamentarlo en la dinámica de una transformación históricogeográfica” (ibid.).

Un cosmopolitismo que busca el cambio debe entenderse a sí mismo como un producto histórico en una ubicación geopolítica. Nederveen Pieterse, Truong y Giri sugieren que contrarrestar la cosmopolitización corporativa requiere perspectivas culturales e históricas más ricas que únicamente las de las tradiciones de la filosofía normativa occidental. Debemos mirar e involucrarnos con movimientos sociales específicos que adoptan, conducen, utilizan y transforman ideas.

Trabajos recientes sobre el liderazgo por medio de ideas en el sistema mundial (que incluyen a Emmerij et al., 2001, 2005, y Murphy, 2005) concluyen que entre las ideas clave con influencia societal están las ideas acerca de los valores. Como un ejemplo central: "las ideas de las Naciones Unidas pueden cambiar la naturaleza del dis- 
curso y el debate internacionales sobre políticas públicas y, como resultado, pueden con frecuencia auxiliar a los Estados a definir o redefinir sus intereses para hacerlos más inclusivos de los intereses comunes" (Emmerij et al., 2005: 218). Sin embargo, De Bono (1985) apunta que puede ser más fácil, relativamente hablando, influir en la gente cambiando visiones que intentar cambiar directamente sus valores. Aún más, las ideas acerca de los valores pueden tener poco impacto sostenido si no se incorporan en metodologías prácticas y propuestas que comuniquen y canalicen una manera de ver, una visión. El cambio de valores individuales no es suficiente ni el fin en sí mismo, si no un complemento y un soporte para el establecimiento de estándares sobre derechos humanos, y otros estándares y fuerzas compensatorias contra los poderes del privilegio, basados en organizaciones fuertes.

Propuestas prácticas concretas que incorporan valores y visiones tienen que ser colocadas en la arena pública, accesibles a reformadores potencialmente interesados, quienes pueden entonces recogerlas por razones propias (Murphy, 2005; Hirschman, 1973). Apoyándose en evidencias de 150 años de evolución de las instituciones globales, Murphy argumenta que en ciertos momentos los manejadores del sistema necesitan nuevas ideas para resolver conflictos y entonces las buscan. Para que los grupos orientados a la justicia hagan una diferencia deben mantener un contacto activo y de cooperación con segmentos progresistas de grupos dominantes y organizaciones internacionales, mantener una red transnacional (para compartir y generar ideas, proveer soporte mutuo y cabildeo, y ofrecer refugio cuando se necesite) y tener una cantidad de ideas y propuestas listas. Thomas Pogge es un ejemplo actual de un filósofo que ha internalizado tal recomendación y busca conectar un re-pensamiento de las teorías de la justicia con la energía de los movimientos sociales (Pogge, 2005). Los escritos de Martha Nussbaum son una contribución de punta para tal repensamiento, que ayuda a inspirar la energía y movimiento requeridos.

\section{Comentarios conclusivos}

Las formulaciones sobre capabilities de Nussbaum deben entenderse como una manera de proceder, como un amplio enfoque al desarrollo ético y humano. Este ensayo se centró no en afinar los detalles de una lista de capabilities, sino en la agenda a la cual una lista puede contribuir y en los otros componentes del enfoque. Así, hemos identificado y considerado otros elementos principales además de aquellos que se refieren directamente a capabilities. Abordamos ideas sobre audiencias y propósitos, conceptos y valores antecedentes, incluyendo los conceptos de emoción y comunidad, y acerca de las fuentes de información del enfoque y los métodos para obtener e interpretar materiales. Consideramos cómo la elección de propósitos y públicos conecta con la elección de métodos y fuentes.

Nussbaum busca una influencia de largo plazo en los marcos constitucionales y legales, y sobre la cultura política, a fin de apuntalar la compasión, el cosmopolitismo y los derechos humanos. Quiere influir en cómo la gente escucha, ve y actúa, y así cambiar a los oyentes, y no sólo los conjuntos informativos de que disponen. Su horizonte temporal es, relativamente, de manera consciente, el largo plazo, como se ve en su énfasis en mejorar la educación escolar y universitaria, especialmente en los países ricos. Esos énfasis coinciden con algunas etapas esenciales, propósitos y públicos para la ética. Vimos que la hipótesis de Sen de que una democracia previene hambrunas confía en la existencia de una comunidad política sentida. Con un débil sentido de comunidad, una escasez discapacitante entre los grupos marginados no recibirá atención ni interés en la metrópoli nacional o regional, mucho menos internacionalmente. Dada la extensión del egoísmo y las estrechas orientaciones a grupos estrechos, tanto global como intranacionalmente, la atención de Nussbaum a las bases del interés en los otros es relevante para la ética política así como para la ética personal. Vemos la pertinencia de su concentración en el análisis y la educación de las emociones, especialmente la compasión. Su enorme agenda conlleva la necesidad de múltiples tipos de evidencia, colaboración e interacción. 


\section{Bibliografía}

Adamson, Jane, 1998, "Against Tidiness: Literature and/versus Moral Philosophy”, en Adamson et al. (eds.), Renegotiating Ethics in Literatura, Philosophy and Theory, Cambridge University Press, Cambridge, pp. 84-110.

Alkire, Sabina, 2002, Valuing Freedoms, Oxford University Press, Oxford y Nueva York.

— Development Ethics: Furthering the Capabilities Approach", Journal of International Development, vol. 9, núm. 2, pp. 263-279.

Beitz, Charles, 1999, "Social and Cosmopolitan Liberalism”, International Affairs, vol. 75, núm. 3, pp. 515-529.

Bono, Edward de, 1985, Conflicts: A Better Way to Resolve Them, Penguin, Londres.

Booth, Wayne, 1961, The Rhetoric of Fiction, University of Chicago Press, Chicago.

Braybrooke, David, 1987, Meeting Needs, Princeton University Press, Princeton.

Brennan, Timothy, 2001, "Cosmopolitanism and Internationalism”, New Left Review, núm. 7, pp. 75-84.

Comte-Sponville, André, 2002, A Short Treatise on the Great Virtues, Heinemann, Londres.

Crocker, David, 1995, "Functioning and Capability. The Foundations of Sen's and Nussbaum's Development Ethic. Part 2", en Nussbaum y Glover (eds.), Women, Culture and Development. A Study of Human Capabilities, Clarendon, Oxford, pp. 153-198.

Diamond, Cora, 1998, "Martha Nussbaum and the Need for Novels", en Adamson et al. (eds.), Renegotiating Ethics in Literature, Philosophy and Theory, Cambridge University Press, Cambridge, pp. 39-64.

Doyal, Len e Ian Gough, 1991, A Theory of Human Need, Macmillan, Londres.

Emmerij, Louis, Richard Jolly y Thomas G. Weiss, 2001, Ahead of the Curve? UN Ideas and Global Challenges, Indiana University Press, Bloomington, Indiana.

_ 2005, "Economic and Social Thinking at the UN in Historical Perspective", Development and Change, vol. 36, núm. 2, pp. 211-35.

Erskine, Toni, 2000, "Embedded Cosmopolitanism and the Case of War: Restraint, Discrimination and Overlapping Communities", Global Society, vol. 14, núm. 4, pp. 569-590.

Gasper, Des, 1996a, "Needs and Basic Needs. A Clarification of Foundational Concepts for Development Ethics and Policy", en G. Köhler (ed.), Questioning Development, Metropolis, Marburg, pp. 71-101. 1996b, "Culture and Development Ethics", Development and Change, vol. 27, núm. 4, pp. 627-661.

__, 1997, "Sen's Capability Approach and Nussbaum's Capabilities Ethic", Journal of International Development, vol. 9, núm. 2, pp. 281-302.

— 2000 , “'Development as Freedom': Moving Economics Beyond Commodities. The Cautious Boldness of Amartya Sen", Journal of International Development, vol. 12, núm. 7, pp. 989-1001.

_, 2003 , "Nussbaum's Capabilities Approach in Perspective. Purposes, Methods and Sources for an Ethics of Human Development", Working Paper 379, Institute of Social Studies, La Haya: <www.iss.nl >.

— 2004, The Ethics of Development, Edinburgh University Press, Edinburgo.

_ 2005 , "Beyond the International Relations Framework: An Essay in Descriptive Ethics”, Journal of Global Ethics, vol. 1, núm. 1, pp. 5-29.

_, 2006 , "Cosmopolitan Presumptions? On Martha Nussbaum and her Commentators", Development and Change, vol. 37, núm. 6.

Gidwani, Vinay, 2006, "Subaltern Cosmopolitanism as Politics”, Antipode, vol. 38, núm. 1, pp. 7-21.

Giri, Ananta, 2006, "Cosmopolitanism and Beyond: Towards a Multiverse of Transformations", Development and Change, vol. 37, núm. 6.

Gough, Ian, 2000, Global Capital, Human Needs and Social Policies, Palgrave, Basingstoke.

__, 2003, "Lists and Thresholds: Reconciling Needs and Nussbaum's Capabilities Approaches”, Working Paper, WeD, University of Bath, Gran Bretaña.

Haines, Simon, 1998, "Deepening the Self: The Language of Ethics and the Language of Literature", en Adamson et al. (eds.), Renegotiating Ethics in Literature, Philosophy and Theory, Cambridge University Press, Cambridge, pp. 21-38.

Harris, Lee, 2003, “The Cosmopolitan Illusion”, Policy Review, núm. 118, pp. 45-60.

Harvey, David, 2000, "Millenial Capitalism and the Culture of Neoliberalism: Cosmopolitanism and the Banality of Geographical Evils", Public Culture, vol. 12, núm. 2, pp. 529-564.

Held, David, 2004, Global Covenant, Polity Press, Cambridge. Hirschman, Albert O., 1973 [1963], Journeys Toward Progress, W. W. Norton, Nueva York.

Küng, Hans, 1997, A Global Ethic for Global Politics and Economics, SCM Press, Londres.

McCloskey, Deirdre, 2006, "Hobbes, Nussbaum and all Seven of the Virtues", Development and Change, vol. 37, núm. 6. 
McLemee, Scott, 2001, "What Makes Martha Nussbaum Run?", The Chronicle of Higher Education, 5 de octubre.

Miller, David y Michael Walzer (eds.), 1995, Pluralism, Justice and Equality, Oxford University Press, Oxford.

Murphy, Craig, 2005, Globalization, Institutions and Development, Routledge, Londres.

_ _ 2006, "International Relations and Responsibility in an Increasingly Unequal World", Development and Change, vol. 37, núm. 6 .

Nair, D. Radhakrishnan, 2000, "Identity, Ideology and Narrative", en Nair y B. Varghese (eds.), The Web of Our Life, Cheerothottam Kudumbayogam, Kothamangalam, India, pp.107-116.

Narayan, Deepa et al. 2000, Voices of the Poor, Oxford University Press, Nueva York, y en: $<$ http://www.worldbank. org/poverty/voices/reports.htm $>$.

Nederveen Pieterse, Jan, 2006, "Emancipatory Cosmopolitanism: Towards an Agenda", Development and Change, vol. 37 , núm. 6.

Nussbaum, Martha C., 1988, "Nature, Function and Capability: Aristotle on Political Distribution”, Oxford Studies in Ancient Philosophy, supl. vol., pp. 145-184.

_ 1992 , "Human Functioning and Social Justice: In Defense of Aristotelian Essentialism”, Political Theory, vol. 20, núm. 2, pp. 202-246.

_, 1993 , "Non-Relative Virtues: An Aristotelian Approach", en Nussbaum y Sen (eds.), The Quality of Life, Clarendon, Oxford, pp. 242-269.

, 1995, Poetic Justice: The Literary Imagination and Public Life, Beacon Press, Boston.

__ 1997, Cultivating Humanity: A Classical Defence of Reform in Liberal Education, Harvard University Press, Cambridge, Massachusetts.

_ _ 1998, "The Literary Imagination in Public Life", en Adamson et al. (eds.), Renegotiating Ethics in Literature, Philosophy and Theory, Cambridge University Press, Cambridge, pp. 222-246. (Tomado de Nussbaum, 1995)

_, 1999 a, Sex and Social Justice, Oxford University Press, Nueva York.

_ 1999 b, entrevista por Cogito, <http://www.philosophy arena.com/philosophyarena> y en A. Pyle (ed.), Philosophers in Conversation: The Cogito Interviews, Routledge, Londres.

_ 2000a, Women and Human Development: the Capabilities Approach, Kali for Women, Cambridge University Press, Delhi, Cambridge.

_ 2000b, "Aristotle, Politics and Human Capabilities: A Response to Antony, Arneson, Charlesworth, and Mulgan”, Ethics, núm. 111, octubre, pp. 102-140.
— , 2001a, Upheavals of Thought. The Intelligence of Emotions, Cambridge University Press, Cambridge.

_, $2001 \mathrm{~b}$, The Fragility of Goodness. Luck and Ethics in Greek Tragedy and Philosophy, ed. revisada, 1ª ed. en 1968, Cambridge University Press, Cambridge.

_, 2004 , "Beyond the Social Contract: Capabilities and Global Justice”, Oxford Development Studies, vol. 32, núm. 1, pp. 3-18.

— 2006 , Frontiers of Justice. Disability, Nationality, Species Membership, Harvard University Press, Cambridge, Massachusetts.

__ y Amartya Sen (eds.), 1993, The Quality of Life, Clarendon, Oxford.

— y J. Glover (eds.), 1995, Women, Culture and Development. A Study of Human Capabilities, Clarendon, Oxford.

— et al. (1996), For Love of Country: Debating the Limits of Patriotism, editado por Joshua Cohen, Beacon Press, Boston, Massachusetts.

O'Neill, Onora, 1996, Towards Justice and Virtue, Cambridge University Press, Cambridge.

- , 2000, Bounds of Justice, Cambridge University Press, Cambridge.

Parker, David, 1998, "Introduction: The Turn to Ethics in the 1990s", en Adamson et al. (eds.), Renegotiating Ethics in Literature, Philosophy and Theory, Cambridge University Press, Cambridge, pp. 1-17.

Pogge, Thomas, 2005, "Recognised and Violated by International Law: the Human Rights of the Global Poor", Leiden Journal of International Law, vol. 18, núm. 4, pp. 717-45.

Raskin, Paul, Tariq Banuri, Gilberto Gallopin, Pablo Gutman, Al Hammond, Robert Kates y Rob Swart, 2002, The Great Transition, SEI-Boston, Stockholm Environment Institute, Boston.

Rawls, John, 1971, A Theory of Justice, Harvard University Press, Cambridge, Massachusetts.

Rustin, Michael, 1995, "Equality in Post-Modern Times", en D. Miller y M. Walzer (eds.), Pluralism, Justice and Equality, Oxford University Press, Oxford, pp. 17-44.

Sen, Amartya, 2000, Development as Freedom, Oxford University Press, Nueva York.

Staveren, Irene van, 2001, The Values of Economics. An Aristotelian Perspective, Routledge, Londres.

Truong, Thanh-Dam, 2006, "One Humanity, Many Consciousnesses: Unresolved Issues on Nussbaum's New Frontiers of Justice", Development and Change, vol. 37, núm. 6.

Walzer, Michael, 1994, Thick and Thin. Moral Argument at Home and Abroad, University of Notre Dame Press, Notre Dame, Indiana. 